\title{
Antisépticos orales. Revisión de la literatura y perspectiva actual
}

\author{
BASCONES A* \\ MORANTE S**
}

Bascones A, Morante S. Antisépticos orales. Revisión de la literatu-
ra y perspectiva actual. Av Periodon Implantol. 2006; 18, 1: 31-59.

\begin{abstract}
RESUMEN
El control de placa bacteriana es el método principal en la prevención de las enfermedades periodontales. Cada vez está más extendido el denominado control químico de la placa de manera complementaria a un control mecánico ineficaz. Los fármacos más utilizados a tal fin son los antisépticos bucodentales, siendo ampliamente aceptada la clorhexidina como el de mayor eficacia. Existen sin embargo numerosas formulaciones de distintos principios activos, ante lo cual, parece justificado revisar la literatura con el objetivo de aclarar la eficacia de los mismos, así como sus diferentes indicaciones.
\end{abstract}

\section{PALABRAS CLAVE}

Clorhexidina/uso terapéutico; placa dental/prevención, control; gingivitis/prevención y control; colutorios/uso terapéutico.

\section{ANTISÉPTICOS EN EL TRATAMIENTO DE LA ENFERMEDAD PERIODONTAL}

\section{INTRODUCCIÓN}

El acúmulo de placa supragingival, conduce inevitablemente a gingivitis (Löe, 1965) y la periodontitis se desarrolla a partir de gingivitis localizada (Lindhe y Löe 1975).

Los mecanismos fisiológicos específicos del huésped y bacterianos, que inducen el paso de gingivitis a periodontitis no son del todo conocidos, por tanto la prevención de la enfermedad periodontal se basa en la disminución del acúmulo de placa. $\mathrm{Si}$ a esto añadimos el insuficiente control mecánico de la misma, bien por técnica incorrecta de cepillado, bien por hábitos higiénicos bucodentales inadecuados en una parte extensa de la población, parece clara la necesidad de utilizar un agente antimicrobiano que complemente el control de la placa bacteriana de forma continuada y eficaz.

La formación de placa es un proceso dinámico y ordenado. Sobre una superficie dentaria limpia se establecen primero los formadores de placa primaria, los estreptococos, cuya presencia es esencial para la adhesión de otras especies bacterianas. Las especies siguientes aportan los medios y la creación de un ambiente adecuado para la adhesión y proliferación de otros microorganismos, aumentando la placa en canti-

* Catedrático de Medicina Bucal y Periodoncia. Director del Máster de Periodoncia. Facultad de Odontología. Universidad Complutense de Madrid.

** Doctor en Odontología. Máster en Periodoncia. Facultad de Odontología. Universidad Complutense de Madrid. 
dad y calidad bacteriana. En la formación ordenada de placa están involucrados procesos de adherencia, proliferación y división bacteriana. La limpieza mecánica actúa sobre la superficie dentaria no esterilizando la superficie sino limitando la masa bacteriana dejando una pequeña placa no patógena que es compatible con salud gingival.

Las sustancias químicas actúan sobre la placa cuantitativa y cualitativamente por los siguientes medios:

- Evitando la adherencia bacteriana, con agentes antiadhesivos. Las sustancias antiputrefacción o los hipocloritos son antiadhesivos, pero son tóxicos en el medio oral, no hay compuestos hoy en día con estas características.

- Deteniendo o retrasando la proliferación bacteriana con antimicrobianos.

- Eliminando la placa establecida con lo que a veces es llamado el "cepillo dental químico".

- Alterando la formación de la placa. Esto no se ha intentado dado la incompleta comprensión de la etiología bacteriana de la gingivitis.

Los agentes inhibitorios más eficaces son aquellos cuya acción persiste en la boca durante el mayor tiempo posible, la persistencia de la acción o sustantividad depende de varios factores:

1. Retención prolongada por adsorción en las superficies bucales, incluidos los dientes cubiertos por película.

2. Conservación de la actividad antimicrobiana una vez adsorbidos.

3. Neutralización mínima o lenta de la actividad antimicrobiana en el medio bucal o lenta desaparición de las superficies.

\section{CARACTERÍSTICAS DE LOS AGENTES ANTIPLACA}

Una revisión de los agentes químicos para el control de placa, exige discutir los requisitos básicos que deben reunir:

2.1. Especificidad: El control de placa no debe basarse en antibióticos, siendo reservados para uso sistémico en infecciones dentales o enfermedades sistémicas específicas.
2.2. Eficacia: la pauta terapéutica viene determinada por la concentración mínima inhibitoria para las bacterias asociadas a patologías dentales. Aceptando la naturaleza no específica de la placa dental (Loesche 1976), las características antimicrobianas de los antisépticos bucales hacen que sean el fármaco de elección.

En el modelo de gingivitis experimental de Löe (1965), en ausencia de control mecánico de la placa durante 21 días, el agente antimicrobiano, debería eliminar placa, prevenir su formación o reducir su cantidad por debajo del nivel patógeno. Esto corrobora la teoría inespecífica de placa, ya que no se atribuye a una bacteria o grupo de bacterias el inicio en la progresión de las enfermedades periodontales, por lo tanto el antimicrobiano de elección debe ser de amplio espectro.

2.3. Sustantividad: Cualidad que mide el tiempo de contacto entre una sustancia y un sustrato en un medio dado. Al tratar infecciones dentales ésta es una cualidad muy importante, ya que el agente antimicrobiano necesita cier to tiempo de contacto con el microorganismo para inhibirlo o eliminarlo, a diferencia de las infecciones sistémicas en las que el tiempo de contacto deseado puede obtenerse mediante aplicaciones periódicas parenterales o enterales del fármaco.

Esta propiedad de los antisépticos ha dado lugar a una clasificación en generaciones (Kornman 1990, Bascones 1991) de los agentes como de primera generación (baja sustantividad) donde clasificamos algunos antibióticos, compuestos de amonio cuaternario, compuestos fenólicos, y agentes oxidantes y fluoruros. Los agentes antimicrobianos de segunda generación (alta sustantividad) son las bisguanidas (clorhexidina). Las sustancias de tercera generación son las que inhiben o interfieren la adhesión bacteriana. Estas sustancias están todavía en vías de estudio.

Para la utilización habitual en clínica los antimicrobianos de segunda generación son los de elección.

Por su potencia de acción se clasifican de alta potencia, los de acción similar a los antibióticos, en este grupo se encuentran la sanguinaria y la clorhexidina. De baja potencia el fluoruro sódico, y de muy baja potencia timol y cetilpiridinio.

2.4. Seguridad: Los agentes antimicrobianos se han ensayado extensamente con lo que su uso está avalado científicamente. La seguridad de un fármaco viene condicionada por su: 
- Permeabilidad. Se deben absorber en el tracto intestinal, y pasar después a torrente sanguíneo. La permeabilidad de la membrana es una característica importante de los agentes de peso molecular relativamente alto como la clorhexidina y la sanguinaria, que se absorben mal y su toxicidad es baja.

- Potencial de toxicidad, debe ser bajo. Los compuestos más tóxicos son las soluciones de fluoruros en concentraciones de 0,2 a 2\% (Bascones 1991), siendo los menos tóxicos, los antibióticos como las tetraciclinas.

2.5. Eficacia intrínseca: es el porcentaje de efecto máximo que puede conseguirse con las limitaciones de solubilidad del agente. No todos los agentes utilizados, son capaces de conseguir por enjuagues una supresión completa del crecimiento bacteriano (Bascones 1991).

La actividad antimicrobiana in vitro de los antisépticos, no es en sí un factor predictivo fiable de la actividad inhibitoria de la placa in vivo, así al comparar la clorhexidina, el compuesto cuaternario de amonio catiónico y cloruro de cetilpiridinio, tienen un perfil similar in vitro, pero la sustantividad in vivo es mucho menor para el cetilpiridinio que para la clorhexidina, lo que se puede suplir aumentando el número de aplicaciones, pero esto puede influir negativamente en el cumplimiento.

Es necesario conocer la respuesta de las siguientes características de los antisépticos en salud:

1. Cuál es el efecto en la flora oral y en la enfermedad.

2. Si este efecto es clínicamente significativo

3. Si se presentan efectos adversos en la flora oral.

4. Si estos efectos se presentan en los tejidos duros o blandos.

5. Si su utilización y propiedades tienen alguna complicación.

\section{SUSTANCIAS UTILIZADAS PARA EL CONTROL DE PLACA DENTAL}

Existen múltiples grupos de sustancias utilizadas en el control de placa:

- Antibióticos: penicilina, vancomicina, kanamicina, espiramicina. Etc.

- Enzimas: proteasa, lipasa, nucleasa, dextranasa, mutanasa, glucosa oxidasa, amiloglucosidasa.
TABLA I.- PROPIEDADES IDEALES DE LOS AGENTES ANTIPLACA

1. Eliminación sólo de las bacterias patógenas.

$1^{\text {a Generación: }}$

- Antibióticos.

- Derivados del amonio cuaternario.

- Compuestos fenólicos.

- Sanguinaria.

- Fluoruros.

- Peróxidos.

$2^{a}$ Generación:

- Clorhexidina, Alexidina.

2. Sustantividad.

3. No facilitar el desarrollo de bacterias resistentes.

4. No ser lesivas para los tejidos bucales a las concentraciones prescritas.

5. No manchar los dientes.

6. No alterar el gusto.

7. Reducir placa bacteriana y gingivitis.

8. Precio accesible.

9. Facilidad de utilización.

10. No desarrollar efectos adversos sobre los dientes.

- Antisépticos bisguanídicos: clorhexidina, alexidina, octenidina.

- Compuestos de amonio cuaternario: cloruro de cetilpiridinio, cloruro de benzalconio.

- Fenoles y aceites esenciales: timol, hexilresorcinol, eucaliptol, triclosan.

- Productos naturales: sanguinaria.

- Fluoruros:sódico, monofluorofosfato sódico, fluoruro estañoso, fluoruro de amima.

- Sales metálicas: estaño, zinc, cobre.

- Agentes oxidantes: peróxido de hidrógeno, peroxiborato sódico, peroxicarbonato sódico.

- Detergentes: laurilsulfato sódico.

- Alcoholes aminados: octapinol, delmopinol.

Comentaremos los más utilizados en la práctica clínica. 


\section{TABLA II.- CLASIFICACIÓN DE LOS ANTISÉPTICOS POR SU ESTRUCTURA QUÍMICA}

1. Componentes fenólicos: fenol, timol, dos fenilfenil, hexilresorcirol listerine (timol, eucaliptol, mentol, metilsalicilato).

2. Componentes de amonio cuaternario: cloruro de cetilpiridiniuim, cloruro de benzetonium, bromuro de domiphen.

3. Agentes oxigenantes, peróxidos, perborato.

4. Extractos de hierbas, sanguinaria.

5. Bisguadinas, clorhexidina, alexidina.

6. Bispiridinas, octanidina.

7. Pirimidinas, hexetidina.

8. Halógenos, iodina, iodoforos, fluoruros.

9. Sales de metales pesados, plata, mercurio, zinc, cobre, estaño.

Adaptado de Newbrun (1985)

\subsection{COMPUESTOS DE AMONIÁCO CUATERNARIO}

Reducen la placa en un 35\%. Su mecanismo de acción parece deberse al aumento de la permeabilidad de la pared bacteriana favoreciendo la lisis y disminuyendo la capacidad de la bacteria para adherirse a la superficie dentaria. Estos compuestos son de eficacia moderada y se eliminan rápidamente de las superficies bucales.

Los efectos colaterales indeseables que tienen son la tinción y sensación de quemazón en la mucosa bucal y lesiones ulcerosas.

Principalmente el cloruro de cetilpiridinio (CPC) que generalmente se usa en pastas dentífricas y colutorios al $0,5 \%$. De acuerdo a los estudios de Harper y cols. en 1995 al comparar una serie de productos comerciales franceses entre los que se encontraba uno cuyo compuesto era CPC al 0,5\% (Alodont $®$ ) con otros, encontró que el CPC era el tercero que producía un menor descenso de carga bacteriana en saliva siendo significativamente inferior a otros compuestos de clorhexidina y hexetidina.

Posteriormente veremos como al añadirlo a clorhexidina potencia los efectos de ésta.

\section{TABLA III.- ANTISÉPTICOS DE USO ORAL}

\begin{tabular}{|c|c|}
\hline Compuesto & Nombre comercial de colutorios \\
\hline Clorhexidina & $\begin{array}{l}\text { Bexident Encías }{ }^{\circledR} \text { al } 0,12 \% \text { y al } 0,2 \% \\
\text { Corsodyl }^{\circledR} 0,2 \% \\
\text { Peridex }^{\circledR} 0,12 \% \text { (EEUU) } \\
\text { Perio-Aid } 0,12 \% \\
\text { Cariax }^{\circledR} \text { Gingival 0,12\% (con fluor 0,05\%) }\end{array}$ \\
\hline Fluoruro de Estaño $\left(\mathrm{SnF}_{2}\right)$ & $\mathrm{Omni}^{\circledR}(\mathrm{EEUU})$ \\
\hline Hexitidina & Oraldine ${ }^{\circledR}$ \\
\hline Sanguinarina & Periogard $^{\circledR}$ \\
\hline Triclosán & Gincilácer $^{\circledR}$ (con cloruro de Zinc $0,20 \%$ ) \\
\hline Compuesto de amonio Cuaternario & $\mathrm{Scope}^{\circledR}(\mathrm{EEUU}), \mathrm{Cepacol}^{\circledR}(\mathrm{EEUU})$ \\
\hline Aceites esenciales & Listerine ${ }^{\circledR}$ \\
\hline Enzimas & Zendium $^{\circledR}$ (pasta) \\
\hline Compuestos que liberan $\mathrm{H}_{2} \mathrm{O}_{2}$ & $\operatorname{Amosan}^{\circledR}$ \\
\hline Detergentes & $\operatorname{Plax}^{\circledR}$ \\
\hline
\end{tabular}




\subsection{FENOLES Y ACEITES ESENCIALES}

Han demostrado una reducción de la placa y gingivitis en un $35 \%$. Se han usado en colutorios y caramelos durante años. El más conocido es el Listerine ${ }^{\circledR}$, que es un aceite esencial mezcla de timol, mentol y eucaliptol combinados con metilsalicilato con un $26,9 \%$ de alcohol y con una presentación en diferentes sabores. Las indicaciones del fabricante son las de utilizarlo como enjuague diario para ayudar al control de la placa bacteriana.

Este producto se debe usar en un enjuague de $20 \mathrm{ml}$ durante 60 segundos dos veces al día ya que se obtiene una reducción del índice de placa de un 12\% mayor utilizándolo 60 seg. que 30 seg. (Ross y cols. 1993). Su efecto bactericida ha quedado probado recientemente por Charles y cols. en 2000, al realizar un recuento de las bacterias vivas en saliva tras realizar un enjuague con una solución acuosa y a la media hora un enjuague de 30 seg con Listerine ${ }^{\circledR}$ o con un control tras $24 \mathrm{~h}$ de ausencia de higiene encontrando que el $78,7 \%$ de las bacterias estaban muertas tras realizar un enjuague con Listerine ${ }^{\circledR}$ y un $27,9 \%$ con el control, al realizar este mismo experimento in vitro, los resultados se correlacionan con los obtenidos in vivo.

También se ha estudiado el efecto a largo plazo como producto de uso diario en casa, así en un estudio patrocinado por la casa comercial en el que se comparan tres grupos de pacientes con gingivitis a los que se les realizó una profilaxis y se les indicó que usaran durante seis meses 1) pasta Colgate control + Listeri$n e^{\circledR}$, 2) pasta Colgate total fluorada + Listerine ${ }^{\circledR} \circ 3$ ) pasta Colgate control+ enjuague control. Observando que a los 6 meses el IP y el IG de los pacientes de los 2 primeros grupos eran menor que el de los pacientes sin Listerine ${ }^{\circledR}$ (Charles y cols. 2001) con significación estadística.

Entre sus efectos adversos podemos destacar su fuerte sabor, que la casa comercial justifica diciendo que al ser un producto norte americano es más fuerte porque a los americanos les gustan los sabores fuertes y de acuerdo a Pontefract y cols. en 2001 tiene un ligero poder erosivo sobre el esmalte. De acuerdo a Addy y cols. 1995 el Listerine ${ }^{\circledR}$ tiñe los dientes en combinación con una ingesta abundante de te, en su estudio, en el que los pacientes bebían cinco tazas de te al día. Estos autores estudiaron la capacidad de tinción de diferentes colutorios como Listerine ${ }^{\circledR}{ }$ Corsodyl $^{\circledR}$ (Clorhexidina $0,2 \%$ ) y dos copolímeros con y sin clorhexidina, observando que tras cuatro días en este régimen, la mayor tinción se producía con el Corsody $l^{\circledR}$ seguido del Listerine ${ }^{\circledR}$, lo que es un factor a tener en cuenta a la hora de usar este producto a largo plazo, este efecto no es mencionado en el estudio de Charles a 6 meses.

Otros efectos secundarios observados han sido: la tinción, el sabor amargo y la sensación de quemazón en la cavidad oral.

\subsection{TRICLOSAN}

Es un antiséptico bisfenol clorado (Martindale, 1993). El triclosan ha sido utilizado en jabones, y pastas de dientes. Solo como colutorio al 0,2\% tiene un efecto inhibitorio moderado de la placa y una sustantividad antimicrobiana de alrededor cinco horas. Su acción se ve reforzada por el agregado de citrato de zinc o por el copolímero éter polivinilmetacrílico del ácido maleico.

Addy y cols. en 1990 demostraron que los efectos sobre el control de placa en un grupo de pacientes que dejaban de cepillarse durante cuatro días era ligeramente mejor con un enjuague con una dilución de pasta de dientes con $\mathrm{NaF}+2 \%$ de éter de polivinilo $+0,3 \%$ de triclosan en $10 \mathrm{ml}$ de agua que con un control de solución salina $(2,26 \pm 0,49 \mathrm{Vs} 2,55 \pm 0,54)$ una solución de clorhexidina al 0,12\% obtuvo unos valores de $1,63 \pm 0,49$.

Mas que beneficios en el control de placa, el triclosan parece tener importancia en control de la gingivitis al tener un papel antiinflamatorio. Tiene un control antiplaca similar al fluoruro sódico pero muy inferior a clorhexidina 0,12\% (Addy, 1990). No se han observado efectos adversos importantes con esta sustancia.

\subsection{FLUORUROS}

Tienen propiedades antiplaca. Los más utilizados localmente son: el fluoruro de estaño, fluoruro de sodio y el fluoruro fosfato acidulado. Parece ser que el mecanismo de acción del fluoruro de estaño es la alteración de la agregación bacteriana y de su metabolismo.

Especialmente indicados en el control de la caries, generalmente administrados en pasta dentífrica. Su efecto a la hora de prevenir la formación de nueva placa dental usándolos como colutorios es similar a la del triclosan, pero estos resultados son muy inferiores a 
los obtenidos con clorhexidina (Addy y cols. 1990). El fabricante recomienda usarlo cada 12 horas.

Un estudio de control de placa desarrollado por Reich y cols. (2001) demuestra mejores resultados para el fluoruro aminoestañoso que para clorhexidina al 0,1\% ambos en solución no alcohólica, lo que parece contradictorio con otros estudios (Addy 1990).

\subsection{HEXETIDINA}

La hexetidina es un derivado de pirimidina al que se le atribuyen propiedades antisépticas así como la de acelerar la cicatrización postcirugía periodontal (Donnazzan, 1963; Leydiger 1961; Simring, 1963).

La hexetidina tiene una acción inhibitoria limitada de la placa. Su acción antiplaca se reforzaría con las sales de Zinc. Su sustantividad es de 1-3 horas, al estudiar su efectividad en la curación de úlceras aftosas, no se encontró ningún beneficio sobre una higiene oral convencional. Además la hexetidina en concentraciones mayores del $0,1 \%$ puede producir úlceras orales.

Al comparar su efecto en forma de spray, con un placebo en la curación de una zona tras una cirugía periodontal, se observó que el IP y el IG eran significativamente menores al usar Hexetidina (Bokor y cols. 1996).

Al comparar el efecto antibacteriano en saliva tras un enjuague de Hextril (hexetidina al 0,2\%) con 4 marcas de clorhexidina, una de CPC y un control, se observó que todos los enjuagues producían una disminución de los recuentos bacterianos a los $30 \mathrm{~min}$. similares, siendo los resultados mejores para Hextril que para el control, Eludril (clorhexidina 0,1\%) y Alodont (CPC 0,005\%), pero a las cinco y siete horas, Hextril obtenía los mismos resultados que la solución de CPC y la clorhexidina al 0,1\% siendo los resultados significativamente peores que con las otras clorhexidinas (Hibident, Paroex, Prexidine), en cuanto al acúmulo de placa, hexetidina obtuvo unos resultados ligeramente peores que las clorhexidinas más efectivas y mejores que el compuesto de CPC y Eludril. (Harper y cols. 1995).

Addy y Wade en 1989 estudiaron la capacidad de tinción de estos mismos productos in vitro, observando que la hexetidina obtenía un nivel de tinción similar a la clorhexidina, en este estudio también se observaba la capacidad antibacteriana in vitro de estos coluto- rios, observando que la hexetidina obtenía unos resultados similares a las clorhexidinas.

Concluiremos diciendo que la hexetidina tiene algún efecto inhibidor de placa y aunque éste se ve mejorado en combinación con $\mathrm{Zn}$, sigue siendo menor en comparación con el efecto antigingivitis y antiplaca de clorhexidina al 0,2\%

\subsection{CLORHEXIDINA}

La clorhexidina es sin duda el antiséptico de elección. Su utilización es amplia y es el agente más efectivo. La reducción de placa y de gingivitis alcanza el $60 \%$. Su mecanismo de acción se realiza mediante una reducción de la formación de la película adquirida y alteración del desarrollo bacteriano y de la inserción al diente. Se presenta de tres formas: digluconato, acetato e hidrocloruro, la mayoría de productos usan el digluconato en concentrados del $20 \%$ o $12 \%$.

La clorhexidina fue desarrollada en la década de los 40 por Imperial Chemical Industries en Inglaterra por científicos en un estudio contra la malaria. En ese momento los investigadores fueron capaces de desarrollar un grupo de compuestos denominados polibisguanidas, que demostraron tener un amplio espectro antibacteriano y salió al mercado en 1954 como antiséptico para heridas de la piel, posteriormente comenzó a usarse en medicina y cirugía tanto para el paciente como para el cirujano. En odontología se utilizó inicialmente para desinfección de la boca y endodoncia. El estudio definitivo que introdujo la clorhexidina en el mundo de la periodoncia fue el realizado por Löe y Schiott en 1970, donde se demostró que un enjuague de 60 segundos dos veces al día con una solución de gluconato de clorhexidina al $0,2 \%$ en ausencia de cepillado normal, inhibía la formación de placa y consecuentemente el desarrollo de gingivitis.

Mecanismo de acción: Este compuesto es una base fuerte dicatiónica a pH superior a 3,5 con dos cargas positivas en cada extremo del puente de hexametileno, es esta naturaleza dicatiónica la que la hace extremadamente interactiva con los aniones, lo que es relevante para su eficacia, seguridad, efectos secundarios locales y dificultad para formularla en productos. Aunque es una base, la clorhexidina se mantiene más estable en forma de sal y la preparación más común es la sal de digluconato por su alta solubilidad en agua (Fardal y Tumbull, 1986). 
Se une fuertemente a la membrana celular bacteriana, lo que a bajas concentraciones produce un aumento de la permeabilidad con filtración de los componentes intracelulares incluido el potasio (efecto bacteriostático), en concentraciones más altas produce la precipitación del citoplasma bacteriano y muerte celular (efecto bactericida). En boca se adsorbe rápidamente a las superficies, incluidos los dientes con película adquirida, proteínas salivales y a la hidroxiapatita.

La clorhexidina adsorbida se libera gradualmente en 8-12 horas en su forma activa (Rolla, 1975). Después de 24 horas aún pueden recuperarse concentraciones bajas de clorhexidina, lo que evita la colonización bacteriana durante ese tiempo (Yankelll, 1982 y Case, 1977) $\mathrm{Su} \mathrm{pH}$ óptimo se encuentra entre 5,5 y 7. En función del $\mathrm{pH}$ ejerce su acción frente a diferentes bacterias. Con un pH entre 5,0 y 8,0 es activa frente a bacterias Gram-positivas y Gram-negativas. El desarrollo de resistencias es muy escaso (AMA Drug Evaluation Annual, 1993). También reduce los microorganismos aerobios y anaerobios de la placa en un 54-97 \% en un periodo de seis meses (PDR, 1993) En un periodo de 2 años no se desarrollan resistencias ni presencia de oportunistas o efectos adversos en la cavidad oral (Löe, 1976).

Los estudios parecen indicar que la acción inhibitoria es únicamente debida a la clorhexidina unida a la superficie de los dientes. Es posible que la molécula se adhiera a la superficie por un catión, dejando los otros libres para interactuar con las bacterias que intentan colonizar la superficie del diente. Esto explicaría por que las pastas con una base de sustancias aniónicas como el lauril sulfato sódico reducen la inhibición de la placa por la clorhexidina si se usan poco después de los colutorios.

Farmacocinética Los estudios farmacocinéticos de clorhexidina, indican que aproximadamente el $30 \%$ del principio activo, se retiene en la cavidad oral después del enjuague. La clorhexidina retenida se libera lentamente en los fluidos orales. Estudios realizados en animales y en humanos demuestran la escasa absorción del fármaco en el tracto gastrointestinal. Los niveles plasmáticos de clorhexidina alcanzan un pico de 0,206 $\mathrm{pg} / \mathrm{g}$ en humanos 30 minutos después de la ingestión de $300 \mathrm{mg}$ de dicho fármaco. No se observaron niveles detectables en plasma de clorhexidina después de 12 horas de la ingesta (PDR, 1993; Martindale, 1993).

La excreción de clorhexidina se realiza fundamentalmente por las heces (90\%); menos del $1 \%$ se excreta por la orina (PDR, 1993; Martindale, 1993).
Concentraciones: la clorhexidina suele presentarse en dos concentraciones, al $0,12 \%$ y al $0,2 \%$, se recomienda realizar un buche con $10 \mathrm{ml}$ de producto a una concentración del $0,2 \%$ y de $15 \mathrm{ml}$ al $0,12 \%$, esto es debido a la dosis total de clorhexidina ya que $10 \mathrm{ml}$ al $0,2 \%$ libera $20 \mathrm{mg}$ y $15 \mathrm{ml}$ al 0,12\% libera $18 \mathrm{mg}$, observándose que los resultados con ambas formulaciones son igual de efectivos.

Las formulaciones de distintos colutorios antisépticos se desarrollaron inicialmente en soluciones alcohólicas.

Las últimas investigaciones van encaminadas a conseguir una formulación de clorhexidina en medio no alcohólico igual de efectiva que la formulación de la misma en solución alcohólica. Según el estudio de Van Steenberghe y cols. (2001) se consigue con una combinación de clorhexidina al 0,12\% sin alcohol a la que se añade cetilpiridinio al 0,5\% (nueva formulación de Perio Aid), resultando igual de efectiva en el control de la formación de nueva placa que clorhexidina con alcohol al 0,12\% (Perio Aid) y que clorhexidina con alcohol al 0,2\% (Corsodyl).

Conclusiones similares reflejan el estudio de Borrajo y cols. 2002 en el que comparan dos formulaciones de

\begin{tabular}{|c|c|c|}
\hline \multicolumn{3}{|c|}{$\begin{array}{l}\text { TABLA VI.- ALCOHOL Y PH } \\
\text { DE DISTINTOS COLUTORIOS*. } \\
\text { VALORES PROMEDIOS }\end{array}$} \\
\hline & Alcohol (\%) & $\mathrm{pH}$ \\
\hline Bexident Encías ${ }^{\circledR}$ & 0 & 6,25 \\
\hline Corsodyl $^{\circledR} \S$ & 7,0 & 6,00 \\
\hline Corsodyl menta ${ }^{\circledR}$ & 7,0 & 6,25 \\
\hline Peridex $^{\circledR}$ & 11,6 & 5,60 \\
\hline Perio-Aid ${ }^{\circledR}$ & 11,6 & 6,50 \\
\hline Cariax $^{\circledR}$ & & 6,65 \\
\hline Listerine $^{\circledR}$ & 26,9 & 4,20 \\
\hline Listerine Cool Mint ${ }^{\circledR}$ & 22,0 & 4,20 \\
\hline Periogard $^{\circledR}$ & 11,5 & 4,50 \\
\hline $\mathrm{Cepacol}^{\circledR 1}$ & 14,0 & 6,00 \\
\hline Scope $^{\circledR}$ I I & 18,5 & 5,50 \\
\hline Oraldine ${ }^{\circledR}$ & 10,0 & 3,90 \\
\hline Gingilácer ${ }^{\circledR}$ & 15,7 & 4,00 \\
\hline
\end{tabular}


clorhexidina, una en medio alcohólico con digluconato de clorhexidina al $0,12 \%$, con fluoruro sódico al $0,05 \%$ y etanol al $11 \%$, frente a una formulación idéntica sin alcohol. Los resultados indican la misma efectividad para ambas formulaciones en control de placa y reducción de la inflamación gingival.

Por otra parte, Segreto y cols. (1986) compararon la eficacia y tolerancia de clorhexidina gluconato de $0,2 \%$ y 0,12 frente a placebo en un estudio a tres meses. Ambas formulaciones se utilizaron dos veces al día, durante 30 segundos y en volumen de $15 \mathrm{ml}$. La dosis diaria de clohexidina fue, pues, de $60 \mathrm{mg}(0,2 \%$ de clohexidina gluconato, dos veces al día) y $36 \mathrm{mg},(0,12$ de clorexidina gluconato, dos veces al día).

Jenkins y cols. (1989) compararon la eficacia y tolerancia de clorhexidina $0,2 \%\left(\right.$ Corsody $\left.^{\circledR}\right)$ frente a clorhexidina $0,1 \%$ (Eludril ${ }^{\circledR}$ ) como agentes antigingivitis y antiplaca. Los índices de placa y gingivitis aumentaron significativamente con clorhexidina $0,1 \%$; asimismo en este grupo de pacientes se produjeron escasas discoloraciones dentales. Basados en tales hallazgos, el grupo investigador concluyó que la reducida actividad antiplaca de clorhexidina $0,1 \%$ se debía a una inadecuada formulación galénica de dicho principio activo, lo cual producía su inactivación, más que la concentración de clorhexidina utilizada.

Es, por lo tanto, muy importante - dada la cantidad de formulaciones de clorhexidina existentes en el mercado- que los fabricantes proporcionen a los profesionales la documentación adecuada (ensayos clínicos controlados, con un diseño experimental correcto) sobre el producto (principio activo y formulación galénica), más que sobre el principio activo al cual consideramos suficientemente documentado. Además, la gran mayoría de los ensayos clínicos publicados con clorhexidina al 0,12\% en $15 \mathrm{ml}$ fueron realizados con Peridex $^{\circledR}$.

Según un estudio realizado en la facultad de odontología de Chile, al comparar concentraciones de clorhexidina de $0,1 \%$ frente a $0,12 \%$ concluyen que la clorhexidina al 0,1\% es capaz de tener actividad antiplaca y antimicrobiana cuando es usada en colutorios, no siendo necesarias concentraciones más elevadas, lo que disminuye el riesgo de aparición de efectos adversos (Yévenes y cols. 2002.)

Los colutorios no alcohólicos de clorhexidina son igualmente efectivos y poseen menos riesgos potenciales que las soluciones hidroalcohólicas. Actualmente, a dichos colutorios se asocian otras sustancias en un intento de mejorar su efectividad y efectos secundarios. Siguiendo un modelo de gingivitis experimental, Bascones y cols. en 2005 analizaron tres colutorios comerciales sin alcohol que, como base, contenían digluconato de clorhexidina al 0,12\% . Mediante un diseño a doble ciego y cruzado, 30 sujetos fueron sometidos a tres fases experimentales consecutivas con los colutorios a valorar: clorhexidina, clorhexidina + fluoruro sódico al 0,05\% y clorhexidina + cloruro de cetilpiridinio al 0,05\%. En cada una de estas fases, y durante un periodo de 21 días, los sujetos cesaron todo tipo de medidas de higiene oral y fueron tratados exclusivamente con el colutorio experimental previamente asignado de forma aleatoria (un enjuague bucal dos veces al día). Cada fase experimental fue precedida por un periodo de 14 días de aclaramiento. Al inicio y al final de cada fase experimental, se determinaron los niveles de gingivitis, de placa y cálculo supragingivales, así como de tinción dental. No encontraron en cuanto a la evolución de los índices gingival y de tinción dental diferencias estadísticamente significativas entre tratamientos. Observaron diferencias en el índice de placa supragingival, siendo clorhexidina- $\mathrm{NaF}$ el tratamiento que presenta un aumento superior. También observaron diferencias en el índice de cálculo supragingival, siendo clorhexidina-CPC el tratamiento con un aumento inferior. Las alteraciones linguales fueron más frecuentes con clorhexidina-CPC $(p=0,0141)$. Concluyen que en colutorios no alcohólicos de clorhexidina, la inclusión de otros principios activos no sólo no aporta efectos beneficiosos, sino que puede disminuir su efecto antiplaca o aumentar la tinción lingual.

Charles y cols. (2004) comparan la acción antiplaca y antigingivitis de un colutorio de clorhexidina al 0,12\% (Peridex) frente a un colutorio de aceites esenciales (Listerine) en un estudio con 108 pacientes divididos en tres grupos, dos test y un control negativo (placebo) sin alterar el control mecánico de placa. Evalúan a 3 y 6 meses y encuentran que a los 6 meses hubo una reducción significativa del índice gingival que fue del 14\% para Listerine y del $18.2 \%$ para clorhexidina. También hubo una reducción significativa del índice de placa del $18.8 \%$ para Listerine y del $21.6 \%$ para la clorhexidina. El grupo clorhexidina presentó significativamente más cálculo y más tinciones extrínsecas que el Listerine por lo que concluyen sería razonable utilizar aceites esenciales en el manejo de pacientes peridodontales.

Espectro antibacteriano. In vitro tiene efectividad frente a Gram-y Gram+ incluyendo aerobios y anaerobios e incluso hongos y levaduras, los compuestos que 
incorporan CPC a la clorhexidina obtienen mejores resultados (Giuliana y cols. 1997).

La función de la pared celular es una capa externa rígida que protege la membrana celular. La adsorción de clorhexidina va a causar una alteración en la movilidad electroforética de todo el microorganismo. Cuando clorhexidina se pone en contacto con la membrana celular su integridad se altera y se facilita la liberación de los componentes intracelulares. A bajas concentraciones se liberan las sustancias de bajo peso molecular como iones potasio y fósforo. A altas concentraciones se presenta una precipitación del contenido citoplasmático. Así, clorhexidina puede ejercer una acción bacteriostática que llega a ser letal cuando la concentración se eleva al causar precipitación citoplasmática o coagulación.

Schiótt (1970) informa que durante un período de cuarenta días utilizando diariamente un buche de $10 \mathrm{ml}$ de clorhexidina al 0,2\% se presentaba una reducción entre el 85 y $90 \%$ del número total de aerobios y anaerobios presentes en la saliva. También describieron una reducción en la población de colonias bacterianas y en la colonización de superficies dentarias.

A bajas concentraciones tiene efecto bacteriostático, a altas concentraciones es bactericida debido a la precipitación o coagulación del citoplasma. La clorhexidina adsorbida gradualmente se libera durante veinticuatro horas, aunque la concentración en la boca disminuye. Por ello reduce la colonización bacteriana de las superficies dentarias.

Rólla y Melson (1975) sugieren que la clorhexidina inhibe la formación de placa por los siguientes mecanismos:

1) Por la unión de grupos ácidos aniónicos en las glicoproteínas salivares y por ello reduciendo la formación de la película y la colonización de la placa.

2) Por la unión con las bacterias salivares y la interferencia con su adsorción al diente.

Emilson (1973) encontró que los Staphylococcus, Streptococcus mutans, S. Salivarius y Eschenchia coli tenían alta susceptibilidad; S. sanguis intermedia y las cadenas de Proteus, Pseudomonas y Klebsiella baja susceptibilidad.

Evans y cols. (1977) informaron que clorhexidina inhibía la formación "in vitro" de la placa con Actinomyces viscosus, A. naeslundü, S. mutans y S. Sanguis.

Schiott y cols. (1973) demostraron una reducción entre un 85 y $90 \%$ del número total de aerobios y anae- robios presentes en saliva después de cuarenta días de un buche diario con $10 \mathrm{ml}$ de clorhexidina al 0,2\% y después de dos años una reducción entre el 30 y $50 \%$ lo que podría hacer pensar en una resistencia.

Hennessey (1973) prueba que los organismos Grampositivos son más sensibles que los Gram-negativos y los estreptococos más que los estafilococos. La clorhexidina también es efectiva contra Candida albicans.

Sekino y cols. (2004) evalúan la capacidad de inhibición deformación de novo de placa del uso de clorhexidina en un modelo de formación de placa de 4 días así como la recolonización bacteriana de placa y saliva. Concluyen sobre los 10 sujetos del estudio que la clorhexidina usado como colutorio combinado con gargarismos y aplicación en lengua, retarda de manera significativa la formación de nueva placa tras 4 días sin control mecánico de la misma. La microbiota a los 4 días fue similar en test y en controles.

La clorhexidina es efectiva en la inhibición de la formación de placa de novo, pero no reduce significativamente la placa en una boca sin tratar, por lo que su uso debe recomendarse tras el tratamiento.

Toxicidad y efectos secundarios: No se ha descrito toxicidad sistémica por aplicación tópica o ingestión, ni hay evidencias de teratogenia en el modelo animal.

No se ha observado resistencia bacteriana, ni en los casos de uso prolongado en boca, ni hubo evidencias de sobreinfección por hongos, levaduras o virus. El uso prolongado en boca produce un leve desplazamiento de la flora hacia microorganismos menos sensibles, pero se revirtió rápidamente a la situación inicial al término del estudio de dos años (Schiott y cols. 1976).

Se han descrito en muy raras ocasiones ciertas sensibilizaciones al fármaco lo mismo que los efectos colaterales sistémicos por la ingestión del compuesto (Case, 1977).

Kenney (1972) informa que dos minutos de exposición a la clorhexidina al 0,2\% puede causar alteración de la membrana celular en algunos polimorfonucleares. Sin embargo, parece que la concentración al 0,2\% puede alterar la pared de los PMN con más facilidad por lo que podría comprometer la relación huésped-parásito.

Riberiro y cols. (2004) encuentran en un modelo experimental animal en ratas que la clorhexidina es capaz de inducir daño primario en el DNA en leucocitos 
y en células de la mucosa oral pero no puede producir rotura del cromosoma en eritrocitos.

\section{POTENCIAL DE DISCOLORACIÓN}

Su efecto adverso más común es la pigmentación marrón de los dientes, de algunos materiales de restauración y de las mucosas sobre todo del dorso de la lengua.

La discoloración de las superficies de los dientes, lengua y mucosa oral es un efecto colateral bien conocido de los productos que contienen clorhexidina. Estas discoloraciones se piensa que pueden estar originadas por la interacción entre las sales de clorhexidina en la boca y los taninos presentes en algunos alimentos (té, vino, etc...) aunque tampoco puede descartarse la concentración y la dosis (Addy, 1991; Addy, 1985). Clorhexidina al $0,1 \%$ produce menos discoloraciones, pero tiene menor eficacia antiplaca y antigingivitis que clorhexidina al 0,12\% (Addy, 1991).

No obstante, de los dos únicos productos de los que se dispone estudios a medio y a largo plazo (de 6 meses a 2 años) (Corsody $l^{\circledR} 0,2$ y Peridex ${ }^{\circledR} 0,12$ ), los porcentajes de discoloraciones dentales son similares y afectan al 50\% y al 56\% de los pacientes (Lóe, 1976; PDR, 1993), respectivamente.

Algunos autores (Ciancio y Nisengard, 1994), afirman que dichos efectos colaterales "se minimizan" con concentraciones de clorhexidina al 0,12\%. No obstante, no aportan datos y/o referencias bibliográficas que permitan avalar tales afirmaciones. Sin embargo, entre ambos productos no son predecibles diferencias significativas en cuanto a eficacia y tolerancia dado que con Corsody ${ }^{\circledR}$, se administran $40 \mathrm{mg}$ de clorhexidina/día $\left(0,2 \%\right.$, en $10 \mathrm{ml}$, dos veces al día) y con Peridex ${ }^{\circledR}, 36 \mathrm{mg}$ de clorhexidina/día (0,12\%, en $15 \mathrm{ml}$, dos veces al día). De otros productos que contienen clorhexidina, desconocemos su eficacia y tolerancia a medio y largo plazo.

Por otra parte, la presencia de discoloraciones dentales puede ser un buen indicador del cumplimiento del tratamiento por parte del paciente.

Tales discoloraciones dentales se solucionan mediante profilaxis profesional.

En cuanto a las discoloraciones que se pueden producir en lengua y mucosa oral con el uso prolongado de clorhexidina, en la bibliografía apenas se aportan datos ni sobre su incidencia ni sobre si este efecto cola- teral es concentración-dependiente. No obstante, en el estudio de Lóe (1976) realizado en 120 pacientes, utilizando clorhexidina $0,2 \%$ una vez al día, durante dos años, no se presentaron discoloraciones linguales o de la mucosa oral; además, el estudio de Segreto y cols. (1986), donde compararon en un estudio a tres meses, realizado en 600 pacientes (200 por grupo de tratamiento), en el que se comparó la eficacia y tolerancia de clorhexidina al $0,2 \%$ y $0,12 \%$ en un volumen de $15 \mathrm{ml}$, frente a placebo. Como agentes antigingivitis y antiplaca, no se produjeron discoloraciones linguales o de la mucosa oral, pero si alteraciones en el sentido del gusto. Tales modificaciones, utilizando el mismo sabor, originó un $12 \%$ de abandonos en el grupo de pacientes tratados con clorhexidina.

La causa por la que la clorhexidina produce tinción no es del todo clara, existiendo distintas teorías al respecto, lo que sí parece claro es que se produce una interacción entre la molécula que por un grupo catiónico está unida a la superficie del diente y por el otro grupo e vez de unirse a bacterias se une a sustancias dietéticas ricas en taninos produciéndose una pigmentación, así productos como el te, el vino tinto o el café potencian la pigmentación (Addy y cols. 1995).

Se están investigando sustancias como la polivinilpirrolidona que posee la capacidad de prevenir las tinciones originadas por clorhexidina (Barnett, 1994), sin embargo Claydon y cols. (2001) no están de acuerdo con esta cualidad ya que en el estudio realizado no encuentran diferencias significativas en la tinción producida por colutorios de clorhexidina al 0,09\% y $0,02 \%$ con o sin polivinilpirrolidona.

Otro efecto secundario descrito frecuentemente es la alteración del gusto, que podría reducirse evitando enjuagarse con agua después de la aplicación de clorhexidina. Un estudio de Straub y cols. (2001) concluye que el alcohol de los colutorios de clorhexidina produce una mayor alteración del gusto que los colutorios en solución no alcohólica.

Se han descrito también (Flötra, 1971) lesiones descamativas en la mucosa alveolar después de buches al $0,2 \%$. La descamación de células epiteliales puede ocurrir más frecuentemente con alta concentración que con baja (Gjermo, 1974).

La baja absorción de la clorhexidina es un factor en su baja toxicidad, se metaboliza en el organismo, absorbiéndose débilmente por mucosa del tracto digestivo y eliminándose por las heces el $90 \%$ del fármaco absorbido y el resto lo hace por orina. Estudios mo- 
nitorizados han determinado que no se acumula en el organismo ni se metaboliza en sustancias lesivas.

Por extrapolación a la dosis letal 50 del ratón, se estima que la DL50 para un hombre adulto de $70 \mathrm{~kg}$ sería de $126.000 \mathrm{mg}$.

Cabe destacar que si una clorhexidina no tiñe los dientes no es efectiva, ya que significa que la segunda molécula catiónica ha reaccionado con algo en la formulación, haciéndola inviable tanto para un efecto beneficioso (unirse a la bacteria) como para uno indeseado (teñir), por ejemplo Eludril (Addy y cols. 1995). Se debe recomendar que el paciente se cepille la boca $30 \mathrm{~min}$. antes del enjuague con clorhexidina para eliminar sustancias provenientes de la dieta que puedan teñir los dientes y mucosas e impedir la interacción entre clorhexidina y laurilsulfato sódico, presente en gran número de dentífricos.

Interacciones: además de la potencial inactivación parcial o total de clorhexidina debido a una inadecuada formulación galénica (Adyy, 1989), debemos considerar la inactivación parcial que se produce utilizando en la misma formulación asociaciones con fluoruro sódico (Cariax) esto ha sido contrastado por distintos estudios; Mendieta (1994), Steenberghe (2001), Bascones (2005).

Otra interacción importante es la que presenta clorhexidina con lauril-sulfato sódico, empleado como excipiente en numerosos dentífricos, por lo que se recomienda el cepillado al menos $30 \mathrm{~min}$. antes de la aplicación de clorhexidina (Barkvoll, 1989).

Van Strydonck y cols. (2004) no encuentran diferencias en el índice de placa en dos estudios experimentales de 4 días enjuagando con clorhexidina entre el grupo de dentífrico con lauril sulfato sódico (SLS) y el grupo de dentífrico sin SLS.

\section{INDICACIONES. ENSAYOS CLÍNICOS}

\section{ACTIVIDAD ANTIPLACA Y ANTIGINGIVITIS}

Las infecciones asociadas a la placa dental, caries y enfermedades periodontales, constituyen la patología de mayor prevalencia en los seres humanos. Así pues, el control de la placa mediante su remoción mecánica y/o química forma parte de los principales objetivos de la odontoestomatología preventiva, medicina oral y periodoncia.

El S. mutans se ha implicado en la etiología de la caries, siendo la clorhexidina un potente supresor de este microorganismo. La asociación directa entre el S. mutans y la caries en el hombre ha estimulado ciertos intentos para suprimir la enfermedad eliminando el microorganismo de la cavidad oral y por ello la utilización de la clorhexidina.

Liljemark y cols. (1979) informaron que "in vitro", la clorhexidina bloqueaba la adherencia a la saliva del $S$. mutans.

Emilson (1981) con la utilización de un gel de clorhexidina cinco minutos diarios durante catorce días, demostraron la reducción o eliminación de S. mutans de la placa con un regreso a los niveles de pretratamiento catorce días más tarde.

En relación con la interacción entre el fluoruro y la clorhexidina (Novikov y cols. 1980) informan de una acción inhibitoria en la progresión de la caries combinándolos en un estudio sobre ratas avistar. Beazley y cols. (1980), encuentran que la cantidad de placa formada y el contenido de ácido lipoteicoico redujeron la sacarosa por una combinación en un programa de buches con fluoruro estañoso y clorhexidina.

En este sentido, Ben Yaakov (1978) informa que la presencia de fluoruro aumenta la afinidad de la clorhexidina por la hidroxiapatita en un estudio "in vitro".

Luoma (1992) utiliza la combinación durante dos años de gluconato de clorhexidina al 0,05\% y fluoruro sódico al $0,04 \%$ en solución a un $\mathrm{pH}$ de 5,9 y llega a la conclusión de que se reduce el 53\% la caries y el $75 \%$ la hemorragia gingival. La tinción de los dientes era mínima y desaparecía con un pulido, aunque solo la presentaban un tercio de los individuos. La utilización de gel redujo la caries interproximal en un $50 \%$ en los niños y también las caries radiculares en los adultos. La clorhexidina en barnices parece prometedora debido a un contacto de tiempo muy corto con el diente, lo que ya es suficiente para reducir el S. mutans.

No obstante, la asociación de moléculas aniónicas como el flúor con moléculas catiónicas como clorhe- 
xidina, cada vez están más cuestionadas, ya que disminuyen la acción de la clorhexidina y del flúor (American Academy of Periodontology, 1994; Mendieta y cols., 1994).

Las enfermedades periodontales están producidas por la placa bacteriana y la estrategia terapéutica debe ir encaminada a la eliminación de los organismos patógenos.

El tratamiento periodontal hasta hace algún tiempo se ha efectuado por métodos mecánicos; sin embargo, como las enfermedades periodontales parecen ser infecciones específicas, producidas por una proliferación de algún componente microbiológico, y no del total de las especies de la placa subgingival, parece lógico que la flora pudiera ser eliminada de una forma biológica y específica con la utilización de un agente antimicrobiano con un complemento de desbridación mecánica de las superficies radiculares.

El concepto inespecífico de la placa bacteriana sólo implica medidas de tipo mecánico para el tratamiento de las enfermedades periodontales.

Sin embargo en los últimos años ha tomado cuerpo y desarrollo el concepto de placa específica postulada por Loesche, 1976; Slots, 1979; Socransky, 1977 y Tanner, 1987, señalando que las enfermedades periodontales no se producen por un crecimiento inespecífico de todos sus componentes microbianos, sino por una proliferación específica de algunos de sus integrantes, principalmente anaerobios como Porphyromonas gingivalis, Prevotolla intermedia, espiroquetas y anaerobios facultativos como Actinobacillus actinomycetemcomitans.

En 1970 Lóe y Schiott demostraron que dos veces diarias de buches con $10 \mathrm{ml}$ de clorhexidina al 0,2\% durante un minuto, tenía como resultado una reducción significativa de la placa. Esta reducción de la placa persistía durante los veintidós días en que se llevó a cabo el estudio.

Un trabajo posterior (Lóe, 1976) informó que la reducción de placa se mantuvo durante los dos años en que duraron los buches de clorhexidina al 0,2\%. Este estudio fue significativo ya que demostró los efectos a largo plazo. En el se estudió el desarrollo de la placa, cálculo, el control de la gingivitis, el cambio en la microbiología oral y los posibles efectos secundarios sistémicos o locales.

El trabajo consistió en controlar sesenta y un estudiantes que utilizaron $10 \mathrm{ml}$ de solución de gluconato de clorhexidina al 0,2\% además del cepillado y profilaxis interdental. El grupo control empleó una solución placebo, cepillado y profilaxis interdental. Los parámetros evaluados fueron índice de placa (Silness y Lóe, 1964), índice gingival (Lóe y Silness, 1963), índice de cálculo (Volpe y cols., 1975). Se hicieron análisis de sangre (Hb, VS, Recuento, etc). La pérdida de inserción periodontal se valoró midiendo la distancia del limite amelocementario hasta el fondo de la bolsa.

Las conclusiones fueron que el grupo de la clorhexidina mostró de forma constante índices de placa significativamente menores que el grupo control.

Todos los resultados demostraron que la clorhexidina redujo la placa y la gingivitis pero produjo tinción dental y una mayor cantidad de cálculo supragingival. La tinción se presentó en el 50\% de los sujetos. La importancia de este trabajo se basa en el estudio a largo plazo que duró dos años con la aplicación una vez al día de clorhexidina al 0,2\%.

Existen estudios de (Gjermo, 1974; Bay, 1978) que demuestran que el cepillado con clorhexidina del 0,6 al $0,8 \%$ reduce la placa y la gingivitis. Además utilizando buches al $0,2 \%$ dos veces al día era tan efectiva como si se utilizase en forma de gel tópico al $2 \%$ una vez al día, para inhibir la placa y la gingivitis en ausencia de higiene oral (Lóe, 1970; Davies, 1970; Addy 1982).

Después del trabajo de Lóe y Schiott (1976) otros autores informaron de la inhibición y formación de nueva placa y de la prevención de la gingivitis utilizando la solución acuosa de $0,2 \%$ de digluconato de clorhexidina dos veces al día en forma de buches.

La efectividad de la clorhexidina en la prevención de la formación inicial de placa y en la dispersión de la placa preformada, ha hecho que el fármaco se utilice en grandes situaciones clínicas donde las técnicas de higiene oral convencionales realizadas en forma diaria son difíciles. Por ello se han utilizado en casos de fracturas de mandíbula donde la fijación intermaxilar impide una correcta higiene así como en tratamientos con ortodoncia donde se dificulta el cepillado adecuado y que fácilmente puede llevar a una gingivitis y afectación periodontal. Por todo ello la clorhexidina se puede utilizar cómo método alternativo de control de placa (Davies, 1970; Davies, 1970; Gjermo, 1974).

Ainamo (1992) informa que después de un buche con clorhexidina durante una semana la hemorragia gingival se presentaba más frecuentemente después de un 
masaje suave del margen gingival que después de la higiene oral mecánica, lo que hablaría en favor de la idea de que la clorhexidina es un método complementario adecuado, pero nunca sustitutivo del cepillado.

Lang y Briner (1984) comparan el efecto de dos colutorios diarios de $10 \mathrm{ml}$ de solución de digluconato de clorhexidina al 0,12\% solución oral, con soluciones de amonio cuaternario (cloruro de cetilpiridinium), un compuesto fenólico (Listerine ${ }^{\circledR}$ ), uno alcaloide (sanguinarina) y un grupo control con un placebo y llegaron a la conclusión de que el grupo de la solución de clorhexidina al 0,12\% reducía la placa el $75 \%$, el grupo que utilizaba el amonio cuaternario un $8 \%$, el compuesto fenólico un $25 \%$ y el alcaloide un $30 \%$. Aunque estos últimos productos inhibían la formación de placa, no evitaban el desarrollo de la gingivitis significativamente más que el placebo. El grupo que utilizaba la clorhexidina mantenía los valores del índice gingival en los niveles anteriores al experimento durante los veintiún días sin higiene oral mecánica.

La posible resistencia de las bacterias a ciertos fármacos parece estar en relación con el resultado de la selección de mutantes que se desarrollan debido a alteraciones cromosómicas o por transferencia de información genética por conjugación. Las mutaciones con clorhexidina son muy raras.

Flótra (1972) estudió un grupo de cincuenta soldados durante cuatro meses, informando que en el $60 \%$ se reducía la placa y en el $24 \%$ la gingivitis. El grupo control que había recibido raspaje y alisado tuvo una reducción de placa del $88 \%$ y el $43 \%$ de gingivitis. Todo esto hablaría que la máxima reducción de placa se debe a un control subgingival, siendo la clorhexidina un método complementario adecuado.

Lang y Raber (1981) informaron que un buche diario con $30 \mathrm{ml}$ de clorhexidina al 0,1\% para eliminar la placa y gingivitis no era efectivo mientras que otros afirmaron que si lo era (Flótra, 1972).

Cumming y Lóe (1973) sugieren que el buche diario debería utilizar $50 \mathrm{ml}$ del clorhexidina al 0,1\% para proporcionar una gran dosis de este fármaco. La cantidad de $10 \mathrm{ml}$ al $2 \%$ aplicada una vez al día también se dio como válido para prevenir la formación de placa. Parecería pues, como si los pacientes respondieran en forma diferente a las distintas concentraciones.

Southard y cols. (1989) estudian el efecto del digluconato de la clorhexidina en irrigación en parámetros clínicos y en el nivel de Poiphyromonas gingivalis de bolsas periodontales. Para ello toman ocho pacientes con periodontitis moderada con y sin raspaje y alisado radicular. En cada paciente se dividió la boca en cuatro cuadrantes, en uno se aplicó raspaje y alisado, otro recibió irrigación de clorhexidina, el tercero raspaje y alisado junto con la irrigación de clorhexidina y el cuarto fue el control. Los índices clínicos y microbiológicos se registraron a las $0,5,7,11$ y 15 semanas. Se midieron los parámetros de índice de placa, índice gingival, profundidad del sondaje, tendencia a hemorragia y nivel de inserción. Se midieron también P. gingivalis. Los resultados demuestran que el raspaje y alisado más clorhexidina reducen $P$. gingivalis significativamente mas que la irrigación o el raspaje solos. Los dos tratamientos unidos demostraron ganancia de inserción. En conclusión junto con el raspaje y alisado se recomienda la utilización de la clorhexidina.

Lang y Brecx (1986) afirman que para la selección de agentes antimicrobianos en la prevención y tratamiento de enfermedades periodontales se debe considerar la especificidad, eficacia, sustantividad, seguridad y estabilidad. Los estudios de los últimos años indican que la clorhexidina cumple estos requisitos junto con un buen control de placa y de gingivitis frente al resto de productos antimicrobianos. Por ello concluyen que es el agente antiplaca y antigingivitis más efectivo de los conocidos hoy día.

Estas pruebas clínicas que se computaron como excelentes a corto plazo para la clorhexidina, se obtuvieron también en los estudios a largo plazo (Lóe, 1976) con los 150 estudiantes que utilizaron un buche diario de clorhexidina al 0,2\% durante dos años. Se demostró una reducción significativa de la placa, gingivitis, número total de anaerobios y S. mutans en la saliva.

Con todos estos datos y estudios se puede señalar que la clorhexidina puede ser utilizada a largo plazo bajo supervisión profesional.

En un estudio a triple-ciego llevado a cabo por Manau y col. (1993) en el que comparan la actividad durante tres meses de un colutorio de clorhexidina, hexetidina y un colutorio con fluoruro estañoso y fluoruro de aminas, como complemento del cepillado, llegan a la conclusión que el más eficaz en el control de placa es la clorhexidina seguido por el de fluoruros. Referente al control de la gingivitis no existen diferencias significativas entre los tres, aunque el grupo de la clor- 
hexidina presentó niveles inferiores de gingivitis y S. mutans.

En un estudio de Briner y cols. (1989) se determina la efectividad de un buche dos veces al día de clorhexidina al $0,12 \%$ contra las bacterias de la placa durante un período a largo plazo de dos años. El estudio fue a doble-ciego y comparado con un placebo, tomando muestras de la placa a los 0,6, 12 y 24 meses.

La muestra fue de cincuenta sujetos y se tomaron del segundo molar inferior derecho e izquierdo. Se tomaron cultivos para estudiar anaerobios, estreptococos, actinomyces, fusobacterias, veillonella y bacteroides negro-pigmentados. La conclusión fue que la clorhexidina al $0,12 \%$ fue altamente efectiva para reducir la muestra microbiológica.

Banting y cols. (1989) determinan la efectividad clínica de la clorhexidina $0,12 \%$ dos veces al día durante dos años. Se midieron parámetros tales como índice gingival, de placa, profundidad de bolsas, muestras de placa, cálculo, etc. Las conclusiones fueron que reduce la gingivitis un $40 \%$, la hemorragia gingival un $50 \%$, la placa supragingival un $35 \%$, la profundidad del sondaje una media de $9 \mathrm{~mm}$ por sujeto, aumenta la formación de cálculo supragingival y presenta una alta proporción de sujetos libres de cálculo subgingival.

Briner y cols. (1986) analizan en muestras de placa supragingival los estreptococos y actinomyces en un estudio a doble-ciego entre clorhexidina al $0,12 \%$ y un placebo. La disminución de gérmenes varió entre el $42-95 \%$.

Grossman y cols. (1986) estudian los efectos del gluconato de clorhexidina al 0,12\% en un trabajo durante seis meses en cuatrocientos treinta pacientes sobre la placa y la gingivitis. Al final del estudio se concluyó que el grupo de clorhexidina tuvo un significativo efecto al disminuir la gingivitis, hemorragia gingival y acumulación de placa en comparación con el grupo control. La clorhexidina demostró ser un complemento importante en la prevención y control de la gingivitis cuando se usa de forma regular.

Maruniak y cols. (1992) evalúan el efecto de tres buches sobre la placa y gingivitis. Los colutorios son, timol, clorhexidina y povidona iodada con peróxido de hidrógeno, junto con un placebo. Se utilizaron como único procedimiento de higiene oral durante catorce días, concluyendo que tanto la clorhexidina como la povidona iodada eran efectivos para controlar la placa y la gingivitis.
Addy y cols. (1991) afirman que uno de los mayores problemas que puede existir en la formulación de una clorhexidina es que los ingredientes que intentan abolir o reducir la tinción pueden hacerlo a expensas de actuar contra la actividad antiplaca.

Siegrist y cols., (1986) comparan los buches dos veces al día durante un período de veintiún días de compuestos fenólicos, sanguinarina, digluconato de clorhexidina al 0,12\% y un placebo. El mejor al final del estudio fue la clorhexidina que redujo la placa entre un 62 y un $99 \%$ frente al placebo. Los otros compuestos no demostraron reducciones significativas de la placa. Todo ello va en favor de señalar que la clorhexidina es el agente terapéutico más efectivo en estudios a corto y largo plazo (dos años) así como un compuesto seguro sin efectos colaterales (Lóe et al 1976, Lang et al. 1982, Grossman et al. 1986). Se demuestra que los agentes de primera generación como la sanguinarina y los compuestos fenólicos con poca sustantividad prácticamente no tienen efecto sobre la placa y gingivitis.

En este sentido Grossman y cols. (1989) también comparan el efecto de la clorhexidina con compuestos fenólicos y sanguinarina sobre la placa dental, durante un estudio de seis meses de duración. El grupo de la clorhexidina al $0,12 \%$ disminuyó la gingivitis un 31\%, la hemorragia gingival el $39 \%$ y la placa el $49 \%$ y fue significativamente mejor que los otros agentes $(p<0,05)$. En relación con la placa los compuestos fenólicos lo disminuyeron un $24 \%$ y la sanguinarina un $12 \%$ con los efectos sobre la gingivitis y la hemorragia gingival no se demostró eficacia ya que no hubo diferencias significativas frente a placebo.

Segreto y cols. (1986) realizaron un estudio en seiscientos adultos con el fin de evaluar la eficacia y tolerancia de clorhexidina $0,2 \%$ en $15 \mathrm{ml}$ (equivalente a $60 \mathrm{mg} /$ día de clorhexidina) frente a clorhexidina $0,12 \%$ en $15 \mathrm{ml}$ (equivalente a $36 \mathrm{mg} /$ día de clorhexidina). Este estudio se realizó durante tres meses y se demostró que clorhexidina fue significativamente superior a placebo, sin que se registraran diferencias estadísticamente significativas entre los grupos de pacientes tratados con clorhexidina.

Gjermo y cols. (1975) sugieren las siguientes conclusiones con el uso de clorhexidina:

1. El número de bacterias en saliva que pueden adsorberse al diente se reducen significativamente.

2. El bloqueo de los grupos ácidos en las glicoproteínas salivares disminuye la adsorción de la proteína a la superficie dentaria. 
Lóe y cols. (1972) estudian en un grupo de sujetos la capacidad de la clorhexidina como agente antibacteriano en personas que toman sacarosa. Para ello hicieron tres grupos, uno con ocho individuos que interrumpieron la higiene oral activa e hicieron nueve enjuagues diarios con un $50 \%$ de sacarosa, otro con ocho individuos que sin higiene oral activa hicieron nueve enjuagues diarios con la sacarosa y dos veces al día con $10 \mathrm{ml}$ de clorhexidina al 0,2\% y el tercer grupo tenía dos subgrupos, uno con cuatro individuos sin higiene oral y dos enjuagues diarios con clorhexidina al $0,2 \%$ y el otro con cuatro individuos también pero con instrucciones para la práctica de dos veces de cepillado diario. El experimento duró veintidós días y al final se concluyó que el grupo que se enjuagó con sacarosa tenía placa; el que utilizaba la sacarosa con clorhexidina tenían poca placa; el subgrupo que se cepillaba correctamente y el que se enjuagaba sólo con clorhexidina no tenían placa. El estado gingival era paralelo al de la placa. Se concluye pues que la prevención de la formación de placa inhibe el desarrollo de gingivitis y caries dental, incluso con frecuentes enjuagues de sacarosa.

O'Neil (1976) en pacientes con gingivitis marginal realiza un estudio doble-ciego entre un grupo con clorhexidina $0,2 \%$ y otro placebo. Una vez más de demuestra que el grupo de la clorhexidina presentó una importante reducción del índice de placa e índice gingival. Por ello se concluye que el complemento de la higiene oral con dos enjuagues diarios de clorhexidina al 0,2\% llevan a una mejora del estado gingival, en especial en áreas interproximales.

Lang y cols. (1982) utilizan la clorhexidina en escolares y midieron placa y gingivitis. El estudio se realizó en ciento cincuenta y ocho niños entre diez y doce años de edad comparando clorhexidina $0,2 \%$ y $0,1 \%$ y placebo. Los grupos que utilizaron la clorhexidina independiente de la concentración demostraron buenos resultados para controlar placa y gingivitis, utilizándolo como complemento de la higiene convencional, Sin embargo, se presentó una menor tinción con la concentración de $0,1 \%$ por lo que los autores a largo plazo y en niños es la que recomiendan.

Moran y Addy (1988) evalúan la clorhexidina al 0,2\% $\left(\right.$ Corsody ${ }^{\circledR}$ ) con la sanguinarina (Veadent ${ }^{\circledR}$ ) para inhibir la placa y la gingivitis sin otras medidas de higiene oral. La clorhexidina demostró un efecto mayor para inhibir placa y gingivitis. El efecto de la sanguinarina sería la mitad. Esto va en relación con la sustantividad de los fármacos. La clorhexidina es de segunda generación y demuestra una mayor sustantividad. Todo ello cuestionaría la eficacia de la sanguinarina.

Moran, Newcombe y Addy (1991) comparan la clorhexidina con los compuestos fenólicos en relación con la placa y gingivitis, así como la capacidad de tinción. La conclusión es que la clorhexidina al $0,2 \%$ ofrece mejores beneficios de higiene oral que los compuestos fenólicos, aunque éste también tiene actividad $\operatorname{cont}^{\mathrm{r} a}$ la placa. La tinción dental se presentó en ambos productos.

Jenons, Addy y Newcombe (1989) valoran sobre placa, gingivitis y tinción dental dos concentraciones de clorhexidina y concluyen que la concentración al 0,1\% no produce tinciones pero que era menos efectiva en el control de placa y gingivitis que la del $0,2 \%$.

Addy y Wright (1978) estudian las propiedades antibacterianas tanto "in vivo" como "in vitro" de la clorhexidina al $0,2 \%$ y de la povidona iodada al 0,1\%. Los resultados indican que esta ejerce un efecto antibacteriano inmediato pero al no retenerse en la cavidad bucal su acción es efímera como controladora de placa y en consecuencia de gingivitis. El valor que se le da a la povidona iodada sería como antiséptico inmediato a la cirugía bucal.

Bergenholtz y Hanstrom (1974) comparan la hexetidina al $0,1 \%$ (Oraldine ${ }^{\circledR}$ ) y la clorhexidina al $0,2 \%$ durante veintiún días demostrando que el control de la placa y el de la gingivitis era mejor con la clorhexidina y que las tinciones se presentaron en ambos grupos.

Collaert y cols. (1992) evaluaron el efecto del delmopinol $0,2 \%$ y clorhexidina $0,2 \%$ en enjuagues. Los parámetros estudiados fueron la placa dental, curación de la gingivitis y microbiología salivar. La reducción de la placa fue menor con el delmopinol que con la clorhexidina y actúa igual que ésta en gingivitis durante corto plazo de catorce días.

\section{PERIODONCIA}

\subsection{GINGIVITIS}

Además de su eficacia frente a la gingivitis marginal asociada a la presencia de placa, clorhexidina ha demostrado efectividad en el tratamiento de la gingivi- 
tis necrosante aguda y crónica. Aparte de la tartrectomía, cepillado e higiene interproximal correctos, durante las dos primeras semanas de tratamiento, constituye una ayuda eficaz para la higiene bucal, el enjuague dos veces al día de clorhexidina $0,2 \%$ (Bascones y Manso, 1994; Kristoffersen y Lie, 1984) o al $0,12 \%$.

\subsection{PERIODONTITIS}

- Además de la administración de tetraciclinas durante dos semanas, eliminación del tejido de granulación tras elevar un colgajo y raspado radicular, tras la cirugía es eficaz el enjuague con solución de clorhexidina $0,2 \%$, dos veces al día durante las dos primeras semanas postquirúrgicas (Lindhe y Slots, 1984).

- El tratamiento convencional de la gingivitis crónica y de la periodontitis consiste en raspaje y alisado radicular con instrucción de higiene oral. En las semanas posteriores a la fase de raspaje y alisado, la resolución del tejido inflamado está en estrecha dependencia del control de placa efectivo y diario. La utilización de la clorhexidina al 0,2 $\%$ en buches o bien al $0,1 \%$ en gel, completa la higiene personal y es efectiva como han demostrado los estudios de Lóe y Schiott, (1970), y Bosman y Powell (1977).

Gjermo (1974) demuestra que es inefectiva para suprimir la placa subgingival en bolsas de tres o más milímetros (Flótra, 1972). Sin embargo, si parece ser un elemento útil combinado con el tratamiento periodontal adecuado.

Flemmig y cols. (1990) estudian la eficacia de una irrigación supragingival con gluconato de clorhexidina al 0,06\% en gingivitis. Se evalúa comparándola con la clorhexidina en buche, irrigación con agua e higiene normal con un dentífrico de fluoruro sódico. Los parámetros estudiados fueron el índice gingival, hemorragia al sondaje, índice de placa, profundidad de bolsa, índice de cálculo y tinción. Este estudio demostró que todos los sistemas eran buenos para tratar la gingivitis, pero el que presentó mejores resultados fue la clorhexidina en irrigación.

Del mismo modo Brownstein y cols. (1990) en gingivitis presentes clínicamente comparan la eficacia de la clorhexidina en irrigación frente al buche y el placebo; como criterio de inclusión admitieron seis luga- res proximales con hemorragia al sondaje. Se hicieron a doble-ciego, cuatro grupos de tratamiento, buche con placebo, buche con clorhexidina $0,12 \%$, placebo en irrigación y clorhexidina en irrigación al 0,06\%. Las conclusiones fueron que tanto la clorhexidina en buches como en irrigación reducen la placa $(p<0,05)$ y que la irrigación oral de gluconato de clorhexidina al $0,06 \%$ es efectiva para reducir la hemorragia al sondaje en casos de gingivitis clínica ya presente.

Sin embargo, los irrigadores bucales fracasan en conseguir un nivel óptimo de control de placa y gingivitis cuando no se complementan con los métodos de higiene mecánica, aunque se han demostrado eficaces en el control de las regiones interproximales y subgingivales.

En pacientes con gingivitis o periodontitis refractaria es preferible utilizar irrigación supragingival con digluconato de clorhexidina al $0,06 \%$ o fluoruro estañoso al 0,02\% (Flemming, 1994).

Sin embargo, la irrigación subgingival ha sido efectiva para reducir la inflamación periodontal y controlar la placa subgingival.

No obstante, los ensayos clínicos controlados, sobre la eficacia y tolerancia de clorhexidina aplicada como irrigación subgingival, son relativamente escasos y no permiten, establecer, de forma inequívoca, su indicación.

\subsection{CIRUGIA PERIODONTAL}

Todos los estudios realizados están de acuerdo que la clorhexidina es un buen complemento terapéutico en el control de la inflamación gingival y en especial en situaciones agudas. Después de la cirugía periodontal y otro tipo de cirugía oral, la capacidad del paciente para controlar la placa está disminuida, por lo que la utilización de la clorhexidina es un buen elemento de ayuda.

Westfelt (1983) comparó los efectos clínicos de la clorhexidina al 0,2\% en buches durante dos minutos, dos veces al día durante los seis meses posteriores a la cirugía periodontal (grupo experimental) y en pacientes con un programa de mantenimiento que incluía limpieza profesional cada dos semanas (grupo control). Después de los seis meses todos los pacientes recibieron un programa que incluía profilaxis mecánica cada tres meses, durante dieciocho meses. El control 
químico demostró un índice gingival y de placa tan bajo como el grupo que recibió profilaxis cada dos semanas.

Por ello se concluye que los buches con clorhexidina pueden ser utilizados como alternativa a la profilaxis profesional regular cada dos semanas posterior a la cirugía periodontal.

Newman y cols. (1989) estudian el efecto de un enjuague con clorhexidina al 0,12\% sobre la recolonización bacteriana después de la cirugía periodontal. Al cabo de las seis semanas se objetivó una importante reducción de la placa bacteriana lo que es un factor asociado en la inflamación gingival y en la cicatrización de la cirugía.

En la prevención de la bacteriemia postextracción, Jokinen (1978) encuentra que la desinfección del campo operatorio con clorhexidina al 0,5\% lleva a una menor frecuencia de bacteriemia en comparación con otros métodos de profilaxis.

Asboe-Jórgensen (1974) demuestran un beneficio importante en la cicatrización de las heridas utilizando un gel de clorhexidina al $2 \%$.

La incorporación del clorhexidina en el polvo del cemento quirúrgico condiciona una significativa menor formación de placa, menos exudado gingival, menos hemorragia y una más rápida cicatrización cuando se comparó con otras zonas operadas en las que se utilizó un placebo (Pluss, 1975).

Por el contrario, en otro estudio realizado por Bay y Langebalk (1978) se indica que no existe efecto adicional en la inhibición de la placa utilizando la clorhexidina en el cemento quirúrgico.

Paunio y cols. (1978) examinaron el efecto directo de la clorhexidina en la cicatrización concluyendo que aquella retrasa la formación del tejido de granulación. Knuuttila (1978) afirma que disminuye el número de leucocitos en el exudado inflamatorio.

\section{ALVEOLITIS}

El control de placa es útil para reducir la alveolitis después de la extracción de terceros molares u otros molares inferiores.
Tjernberg (1979) demuestra que en el grupo experimental cuando los dientes se pulieron diariamente durante los cinco días del postoperatorio y se utilizaron buches de clorhexidina al $0,2 \%$ dos veces al día, la alveolitis solo se presentó en un paciente de comparación con el grupo control en que se presentaron cinco casos.

Así mismo, Field y cols. 1988 demostraron que la irrigación y enjuague preoperatorio con clorhexidina $0,2 \%$ disminuye significativamente la incidencia de alveolitis postextracción de molares o premolares inferiores.

Veksler y cols. (1991) señalan una efectividad importante con la clorhexidina al $0,12 \%$ cuando se utilizó después de la cirugía periodontal y en la disminución de alveolitis después de extracciones de terceros molares. El trabajo se basa en la utilización de buches antes del tratamiento dental con el fin de reducir los niveles bacterianos salivares en la cavidad oral lo cual no solo protegería a los pacientes sino también a la profesión dental durante la manipulación en boca.

Ragno y col. (1991) evalúan la utilización de un buche de clorhexidina al 0,12\% para disminuir la incidencia de osteítis alveolar después de la extracción de terceros molares, demostrando el efecto positivo para evitar las alveolitis siempre que se utilice durante la primera semana del postoperatorio.

No obstante, Berwick y Lessin (1990), no encontraron diferencias significativas entre clorhexidina $0,12 \%$, cetilpiridinio $0,05 \%$ y solución salina, utilizados como enjuague preoperatorio e irrigación inmediata postextracción del tercer molar inferior, en la prevención de la alveolitis.

\section{ESTOMATITIS POR DENTADURAS (CANDIDIASIS SUBPLACA)}

Olsen (1975) sugiere para el tratamiento de la estomatitis por dentaduras el uso diario de anfotericina B durante catorce días y sumergir la prótesis en clorhexidina al $0,2 \%$ en la noche, durante cinco meses. Esto disminuye significativamente el número de microorganismos tanto en la muchos como en la prótesis. Jacobsen (1979) también aconseja la utilización de clorhexidina al $1 \%$ lo que disminuye la clínica entre un 71 y un $96 \%$ y los cultivos después de treinta y cinco días de tratamiento. 
Budtz Jorgensen (1977) afir mó que la clorhexidina no puede ser recomendada como desinfección rutinaria de las prótesis debido a los problemas que plantea con las tinciones y la relativa resistencia de los hongos a la acción del fármaco. Sin embargo, si se aconseja en desinfección de prótesis en pacientes que tienen una gran susceptibilidad de diseminación de candidiasis sistémica.

Addy y Hunter (1987) vuelven a demostrar que en pacientes con relativa buena higiene oral la clorhexidina tiene un efecto positivo en el control de placa, en el tratamiento de las candidiasis subplaca y en la aftosis crónica recidivante.

En casos de estomatitis por dentadura la infección inicial está causada por contaminación de las prótesis por los hongos. La clorhexidina se utiliza en estos casos como desinfectante a una concentración entre el 0,2\% y el $2 \%$. (Budtz Jórgensen, 1977). Clorhexidina reduce el número de células infectadas por el hongo en la mucosa palatina y mejora significativamente los tejidos inflamados. Sin embargo, no recomienda su utilización rutinaria por la relativa resistencia de los hongos a la acción del fármaco, el cuál también puede utilizarse como desinfectante de las prótesis durante la noche.

La eficacia de la anfotericina B y la clorhexidina fue comparable, lo que habla en favor del efecto antifúngico en la cavidad oral de la clorhexidina y coincide con los trabajos de Budtz-Jórgensen y Lóe 1972 y Olsen y Lókken 1974).

\section{ULCERACIONES AFTOSAS}

Addy (1977) informa que los buches de clorhexidina $0,2 \%$ reducen significativamente la incidencia, severidad y duración de las ulceraciones aftosas, mientras que en forma de gel se reduce sólo la severidad y duración pero no la incidencia. En este sentido también Piccione (1979) encuentra que los buches de clorhexidina o la utilización en pasta acelera la regresión de la ulceración aftosa recidivante.

Hunter (1987) llevan a cabo un estudio durante seis semanas comparando la clorhexidina al $0,2 \%$ en buches (tres al día) y un placebo. El fármaco reduce el número de días con la úlcera caso como también aumenta el período entre los distintos episodios recurrentes, mejorando la intensidad del dolor.
La etiología de las lesiones mucosas de aftas recidivantes es desconocida y por ello el tratamiento es meramente sintomático con eliminación de los factores predisponentes. La gravedad y duración de las úlceras se aumenta por la contaminación bacteriana y por ello la utilización de gluconato de clorhexidina en buches al 0,2\% o incluso al 0,1\% en gel es recomendado por Addyen 1977.

\section{HALITOSIS}

Aunque existen algunas causas extraorales de mal aliento, aproximadamente el $90 \%$ de las halitosis proceden de la cavidad oral. Más específicamente, el $40 \%$ se origina en el tercio posterior del dorso de la lengua (Delanghe y cols. 1999). La gingivitis y la periodontitis, se han relacionado también como posibles causas de la halitosis oral (Yaegaki y Coil 2000).

El principal componente del mal aliento son los compuestos sulfurados volátiles como resultado de la degradación proteolítica anaeróbica de compuestos de azufre presentes en detritus alimenticios, así como saliva, sangre y células epiteliales. Por tanto la reducción de la carga bacteriana subgingival mediante tratamiento periodontal junto a la reducción bacteriana de otros nichos orales como lengua y mucosas mediante cepillado y clorhexidina, son las opciones terapéuticas más efectivas para el tratamiento de la halitosis.

Carvalho y cols. 2004 realizan un estudio clínico con un modelo de uso en casa de 4 días con supresión de control mecánico de placa para evaluar el impacto del uso de 4 colutorios en el mal aliento de la mañana. Los colutorios testados fueron triclosan al 0,03\%, clorhexidina al 0,12\%, aceites esenciales, y CPC al 0,05\%, placebo como control negativo, y clorhexidina la $0,2 \%$ como control positivo. La disminución de más a menos en la formación de compuestos sulfurados volátiles fue clorhexidina al 0,2\%, clorhexidina al 0,12\%, triclosan, aceites esenciales y cloruro de cetilpiridinio. La formación de placa fue sólo inhibida por clorhexidina y aceites esenciales.

Tanto clorhexidina al 0,2\% en solución alcohólica como al 0,05\% sin alcohol son eficaces coadyuvando con una mejora del control mecánico (cepillado de lengua) en el control de la halitosis de origen oral (Roldan y cols. 2005, Quirynen y cols. 2005). 


\section{OTROS}

La aplicación en períodos a corto plazo y en forma intermitente se ha demostrado útil en la prevención de estomatitis repetidas por prótesis (Budtz-Jórgensen, Lóe 1972) en mantenimiento periodontal con el fin de retrasar el período entre las visitas, en pacientes incapacitados (Bay, Rusell 1975; Usher 1975).

También se ha utilizado con éxito en pacientes con alta tasa de actividad de caries y niveles de S. mutans de más de 250,000 por ml (Zickert, 1982) y últimamente en implantología oral por la importancia que tiene el mantenimiento en estos pacientes.

Las aplicaciones al largo plazo tanto por su seguridad como por su eficacia también pueden ser recomendadas. La profilaxis cada seis meses puede controlar el efecto colateral de la tinción dentaria que se presenta en los pacientes, aunque esta varía en intensidad y extensión.

La clorhexidina se ha recomendado en pacientes discapacitados. Rusell y Bay (1978) recomiendan el cepillado una vez al día durante dos meses con clorhexidina en pasta al 1\%, lo que lleva a una disminución significativa del índice de placa e índice gingival en niños con alteraciones mentales y epilepsia que estaban bajo tratamiento con fenitoína.

Hunter y Addy (1987) en un grupo de incapacitados comparan la eficacia del gluconato de clorhexidina al $0,2 \%$ en enjuagues, al $0,2 \%$ en Spray y al $1 \%$ en gel en cubetas para el control de placa y gingivitis. Los tres métodos señalan mejora de ambos parámetros, sin embargo el gel era más efectivo que el spray y el enjuague. No hubo diferencias en la tinción dental.

Estaría indicado en los pacientes que tienen una resistencia reducida a las bacterias de la placa debido a problemas médicos como agranulocitosis, leucemia, hemorragia, trombocitopenia, alergia, trasplante de médula, SIDA, enfermedades renales, etc. o bien que hayan sido tratadas con citotóxicos inmunosupresores, radioterapia, etc. (Case, 1980; Ferretti, 1985; Spiers, 1980).

Otra indicación importante son los paciente incapacitados (Flótra, 1971) como los que presentan artritis reumatoide, esclerodermia, alteraciones de la motilidad, coordinación muscular o masticación. También se señalan indicaciones de pacientes bajo tratamiento or- todóncico, fijaciones intermaxilares, prótesis y en general en los paciente geriátricos (Heyden, 1971).

Sin embargo, a pesar de que todos los estudios están de acuerdo en la buena eficacia y resultados de la clorhexidina también insisten en que deben aplicarse bajo supervisión profesional y siempre adaptados a cada paciente y caso particular.

\section{PRESCRIPCIÓN}

Debido a todo lo anteriormente reseñado, deberemos recomendar enjuagues de clorhexidina durante periodos de 2 semanas en aquellas situaciones en las que la higiene oral se encuentre dificultada o imposibilitada como:

- Auxiliar de la higiene bucal y de la profilaxis profesional: en la preparación prequirúrgica de los pacientes periodontales, Fine y cols. demostraron que un enjuague con clorhexidina previo a una profilaxis disminuye considerablemente la cantidad de bacterias circulantes en aerosol, disminuyendo la posible contaminación de paciente a dentista.

- Después de la cirugía bucal, incluida la periodontal o el RAR: previniendo la formación de placa en los momentos en que la higiene puede ser más dificultosa.

- En pacientes con fijación de mandíbula.

- En discapacitados físicos y psíquicos.

- En pacientes médicamente predispuestos a las infecciones bucales: transplantados de médula, radiados, leucémicos, VIH., etc.

- En pacientes con alto riesgo de caries ya que la clorhexidina reduce considerablemente el número de S. Mutans en las personas propensas a la caries.

- Úlceras bucales recurrentes: reduce la incidencia, duración y gravedad de las úlceras aftosas recurrentes.

- En pacientes portadores de aparatos ortodóncicos donde el control de placa en las primeras semanas es complicado.

La clorhexidina no tiene capacidad de penetrar en los surcos o bolsas gingivales, por lo que no tiene sentido como tratamiento de la periodontitis.

\section{PRESENTACIONES}

- Colutorios: principalmente en dos concentraciones $(0,12 \%$ y $0,2 \%)$ que a dosis total similar tienen unos resultados muy parecidos. 
- Gel: al 0,2 \% o al 0,12\% para aplicación en localizaciones concretas. Pai y cols. (2004) comparan en un estudio a 6 semanas en 48 pacientes la capacidad antiplaca y antigingivitis de un colutorio de clorhexidina al $0,2 \%$ frente a dos antisépticos en gel, uno de clorhexidina al $0,2 \%$ y el otro de extracto de neem al $0,5 \%$ y otro gel placebo como control negativo. A los 6 meses de estudio encuentran que el gel de clorhexidina redujo los índices de placa y gingival más que el colutorio de clorhexidina con significación estadística. No hubo diferencias significativas en los índices de estudio entre el gel de clorhexidina y el gel de extracto de neem

- Sprays: especialmente recomendados para discapacitados físicos. Francetti y cols. (2004) realizan un estudio ramdomizado controlado comparando tras cirugía de implantes el uso de clorhexidina al 0,12\% en colutorio frente a clorhexidina al 0,2\% en espray. A los 14 días no se encuentran diferencias significativas en el índice de placa pero el espray tiñó significativamente menos que el colutorio.

- Dentífricos: es difícil formular la clorhexidina dentro de una crema dental.

- Barnices: como prevención de la caries radicular. Sin embargo no son eficaces en control de placa al compararlos con colutorios (Cosyn 2005)

- Irrigadores: fracasan en conseguir un buen control de placa y gingivitis cuando no se combinan con medidas de higiene mecánica, aunque se han demostrado eficaces en el control de las regiones interproximales y subgingivales. Sin embargo han sido eficaces para reducir la inflamación periodontal y controlar la placa subgingival.

- Dispositivos de Liberación lenta: El primer trabajo para tratar la enfermedad periodontal con agentes antibacterianos desde el interior de bolsas periodontales fue realizado por Lindhe 1979 colocando fibras huecas de acetato de celulosa permeable (200 mm de diámetro interno y $25 \mathrm{~mm}$ de grosor) rellenas de una solución de hidrocloruro de tetraciclina al $20 \%$, durante veinticuatro horas. Las fibras se toleraron bien y las espiroquetas prácticamente desaparecieron. . Comparando esta técnica con el raspaje y alisado, durante dos días de permanencia de las fibras, demostró un importante cambio en la flora subgingival y eliminación de los síntomas clínicos periodontales, aunque el efecto no era tan marcado como con el raspaje convencional.

Coventry y Newman (1982) en un tubo de diálisis relleno de clorhexidina al $20 \%$ y colocado en la bolsa durante siete días demostraron disminución de hemorragia al sondaje.
Addy (1982) utilizó clorhexidina, metronidazol y tetraciclina en los tubos. En todos los casos se ha demostrado su utilidad, aunque por el momento es necesario más estudios experimentales para su utilización profesional.

Las fibras dentro de la bolsa establecen y mantienen una concentración con el fluido gingival de $600 \mathrm{mg} / \mathrm{m}^{2} \mathrm{du}-$ rante diez días. Las características ideales de un fármaco que se utiliza con estos fines son: toxicidad, potencia, permeabilidad, eficacia intrínseca y sustantividad.

\section{Chips de Clorhexidina (Periochip@)}

Su presentación se compone de una matriz de gelatina biodegradable con $2,5 \mathrm{mg}$ de digluconato de clorhexidina. Las concentraciones subgingivales alcanzadas superan los $125 \mu \mathrm{g} / \mathrm{ml}$, sostenidas durante 7-10 días. Los estudios de evaluación como coadyuvante al raspado encuentran mejor respuesta frente a raspado sólo (Soskolne, 1997; Jeffcoat, 1998, 2000); disminución de la profundidad de sondaje (media $1,77 \mathrm{~mm}$ ) y ganancia de inserción (media 0,98 mm).

No encuentran efecto microbiológico adicional (Daneshmand, 2000) ni beneficio adicional a 9 meses frente al grupo control.

Grisi 2002 en un estudio con 20 pacientes aplican posraspado el periochip en localizaciones con profundidad de bolsa $>4 \mathrm{~mm}$ y sangrado al sondaje, y lo comparan frente a raspado sólo. Encuentran una reducción de bolsa de 2,2 $\mathrm{mm}$ en las localizaciones test frente a 2.4 de los controles. La ganancia de inserción clínica fue de $0,6 \mathrm{~mm}$ en los test frente a 1,0 en los controles.

Los resultados en cuanto a la eficacia de los chips de clorhexidina son contradictorios por lo que son necesarios mas estudios para poder afirmar que su efecto coadyuvante al raspado mejora los parámetros periodontales cuando se compara con raspado y alisado radicular sólo.

Formulaciones comerciales: la presentación que más frecuentemente utilizamos es el colutorio, encontrándonos en el mercado diferentes marcas comerciales cuyo compuesto principal es la clorhexidina pero su formulación difiere según el fabricante.

Así encontramos los siguientes productos (los más conocidos): 
- Bexident Encías: Clorhexidina al 0,12 y 0,2 \% sin alcohol + alantoína + dexpantenol.

- Paroex: Clorhexidina al 0,12\% sin alcohol. Recientemente comercializada en España, existen estudios franceses que demuestran su eficacia.

- Cariax gingival: Clorhexidina al 0,12\% sin alcohol $+\mathrm{NaF}$.

- PerioAid: Clorhexidina al 0,12\% con un $11,6 \%$ de alcohol.

- PerioAid sin alcohol: Clorhexidina al 0,12\% + cloruro de cetilpiridinio $0,05 \%$.

- Clorhexidina Lacer: Clorhexidina al 0,12\% sin alcohol.

- Eludril: Clorhexidina al 0,1 + clorbutanol

- Corsodyl: Clorhexidina al 0,2\% con alcohol al 0,7\%, es la más usada en Estados Unidos.

- Halita: Baja concentración de CHD, indicado en el tratamiento de la halitosis.

- PerioAid mantenimiento: Clorhexidina al 0,05\% + CPC al 0,05\%, indicado como colutorio de uso diario en los pacientes en mantenimiento, no hay artículos publicados.

\section{¿SON TODOS LOS COLUTORIOS DE CLORHEXIDINA IGUAL DE EFECTIVOS?}

De acuerdo a diferentes estudios, el resto de compuestos incluidos en la clorhexidina tienen importancia en los resultados clínicos.

Los estudios de Addy y cols. 1995 y Harper y cols. 1995 evalúan la eficacia de un grupo de productos franceses como: Hibident (CHD 0,2\%), Hextril (Hexetidina 0,2\%), Paroex (CHD 0,12\%), Alodont (CPC 0,005\%), Prexedine (CHD 0,12\%), Eludril (CHD 0,1\%) y un control (solución salina), en estos estudios encontraron que los resultados en el recuento bacteriano en saliva a las 7 horas eran significativamente mejores para Hibident $(0,2 \%)$ y prexidine $(0,12 \%)$ en un tercer lugar Paroex $(0,12 \%)$, en cuanto al índice de placa a los 4 días todas las CHD obtuvieron unos resultados similares excepto Eludril, la hexetidina también obtuvo unos resultados inferiores. En cuanto a la capacidad de tinción in vitro observaron que todas las clorhexidinas tenían unos resultados similares a excepción de Eludril que al igual que alodont (CPC) produjeron escasa tinción en comparación al control, la hexetidina obtuvo unos resultados similares a las clorhexidinas.

En España, un estudio realizado em la U.C.M.es el de Herrera y cols. en 2001 , donde se valoró la eficacia mi- crobiológica de distintos colutorios de clorhexidina al $0,12 \%$ a las 7 horas de un enjuague con diferentes formulaciones por cambios en el contenido de alcohol, o por la adición de otros componentes. Se evaluaron los siguientes productos:

- PerioAid: Clorhexidina al 0,12 con alcohol al 5\%.

- Clorhexidina Lacer: Clorhexidina sin alcohol al $0,12 \%$.

- Cariax: Clorhexidina al 0,12\% sin alcohol + fluoruro sódico.

- PerioAid sin alcohol: Clorhexidina al 0,12\% sin alcohol + cloruro de cetilpiridinio.

Se observó: PerioAid sin alcohol, PerioAid y Lacer obtienen unos resultados similares a las 7 horas siendo ligeramente mejores para bacterias aerobias con PerioAid y para anaerobias con PerioAid sin alcohol, los resultados a los 5 minutos son significativamente mejores con PerioAid sin alcohol para ambos grupos bacterianos.

Estos resultados se correlacionan con los obtenidos por Quirynen y cols. en 2001.

\section{¿CUÁL ES LA CONCENTRACIÓN MÍNIMA EFICAZ?}

Santos y cols. (2004) evalúan la actividad clínica y microbiológica de un colutorio de clorhexidina al 0,05\% con Cloruro de cetilpiridinio al $0,05 \%$ en un estudio de uso en casa 15 días, como apoyo al control mecánico en pacientes periodontales en mantenimiento. Concluyen sobre los 33 pacientes del estudio que encuentran una reducción significativa del índice de placa y en el número de recuento bacteriano en los test frente a los controles.

Quirynen y cols. (2005) comparan clorhexidina con alcohol al 0,2\% frente clorhexidina 0,05\% sin alcohol con cloruro de cetilpiridinio en pacientes posraspado durante 6 meses en mantenimiento. No encuentran diferencias en los índices de placa y gingival. La concentración al $0,05 \%$ produjo menos tinción y alteración del gusto que clorhexidina al $0,2 \%$.

\section{CONCLUSIONES}

- Clorhexidina es el antiséptico más eficaz, pero se debe usar en períodos de tiempo cortos de 2 semanas en situaciones en las que la higiene se vea 
disminuida sin embargo los estudios demuestran que su utilización a largo plazo no produce resistencias bacterianas, aunque debería controlarse la aparición de tinciones con profilaxis periódicas.

- La composición de la clorhexidina influye, siendo importantes el resto de componentes ya que como el fluoruro sódico disminuye la eficacia de clorhexidina.

- Listerine ha demostrado ayudar en el control de placa diario, por lo que puede ser un colutorio válido para pacientes en mantenimiento.

- Hexetidina no demuestra tener unos resultados relevantes en el control de placa aunque éste mejora cuando se añaden sales de zinc

- La formulación no alcohólica de clorhexidina es igual de eficaz que la solución alcohólica.

- Los componentes añadidos a la clorhexidina para disminuir el índice de tinción puede disminuir la eficacia de la misma.

\section{ABSTRACT}

The plaque control is the main method in the prevention of periodontal diseases. It's well known the use of chemical plaque control as a complement to unadequate mechanical control. The most used drugs have been the oral antiseptics, being the chlorhexidine the gold standar. There are many formulations with different chemical components; therefore it seems to be useful to review their properties, efficacy and indications.

\section{KEY WORDS}

Chlorhexidine/therapeutic use; dental plaque/ prevention \& control; gingivitis/prevention \& control; mouthwashes/therapeutic use.

\section{CORRESPONDENCIA}

Antonio Bascones Martínez

Catedrático y Director de Departamento

Facultad de Odontología

Universidad Complutense de Madrid

C/ Ramón y Cajal, s/n

28040 Madrid

Tel: 915334212

Fax: 915345860

E-mail: antbasco@odon.ucm.es

\section{BIBLIOGRAFÍA}

1. Addy M, Jenkins S, Newcombe R. The effect of triclosan, stannous fluoride and clorhexidine on: (I) plaque regrowth over a 4-day period. J Clin Periodontol 1990; 17:693-7.

2. Addy M, Moran J y Newcombe R. A comparison of $0,12 \%$ and $0,1 \%$ chlorhexidine mouthrinses on the development of plague and gingivitis. Clin Prevent Dent 1991; 13: $26-9$.

3. Addy M, Moran J, Newcombe R, Warren P. The comparative tea stainning potencial of phenolic, clorhexidine and antiadhesive mouthrinses. J Clin Periodontol 1995; 22: 923-8.

4. Addy M, Wade WG, Jenkins S y Gooldfield S. Comparison of two commercially available clorhexidine mouthrinses: I stainning and antimicrobial effects in vitro. Clin Prevent Dent 1989; 11: 10-4.

5. Addy M, Moran J, Griffiths AA y Wills-Wood NJ. Extrinsic tooth discoloration by metals and chlorxexidine. I. Surface protein desnaturation or dietary precipitation? Br Dent J 1985; 159:281-5.

6. Addy M y cols. The effect of single morning and evening rinses of chlorhexidine on the development of tooth staining and plaque accumulatio. $A$ blind cross-over trial. J Clin Periodontol 1982; 9:134-40.

7. Addy $\mathrm{M}$ y Hunter $\mathrm{L}$. The effects of a $0,2 \%$ clorhexidine gluconate mouthrinse on plaque, toothstainning and candida in aphthous ulcer patients. A double blind placebo controlled cross- over study. J Clin Periodontol 1987; 14:267-73.

8. Addy M y Wright R. Comparison of the "in vivo" and "in vitro" antibacterial properties of povidone iodine and chlorhexidine gluconate mouthrinses. J Clin Periodontol 1978; 5:198-205.

9. Addy M. Hibitane in the treatment of aphthous ulceration. J Clín Periodontol 1977; 4: 108-16.

10. Addy M, Rawle L, Handley R, Newman HN, Coventry JF. The development and in vitro evaluation of acrylic strips and dialysis tubing for local drug delivery. J Periodontol 1982. Nov; 53(11): 693-9. 
11. Ainamo J, Asikainen S y Paloheimo L. Gingival bleeding after chlorhexidine mouthrinses. J Clin Periodontol 1982: 9: 337-·15.

12. Al-Tannir M, Goodman H. A review of clorhexidine and its use in special populations. Spec Care Dent 1994;14: 116-22.

13. American Medical Association. Topica drugs used in ear, skin and mucous membrane infections. En: AMA Drugs Evaluations Annual. Chicago, American Medical Association 1993:1549-92.

14. Asboe-Jórgensen V, Attstróm R, Land NP y Lóe H. Effect of chlorhexidine dressing on healing alter periodontal surgery. J Periodontol 1974; 45: 13-7.

15. Ashley K. Las propiedades antimicrobianas de dos colutorios antisépticos de uso corriente Corsodyl (clorhexidina) y Oraldine (Hexetidina). Journal of Applied Bacteriology 1984;56: 221-5.

16. Aursnes J. Cochlear damage from chlorhexidine in guinea pigs. Acta Otolaryngol 1981;92:259-71.

17. Baca. Efectividad del barniz de clorhexidina y timol ervitec en los recuentos salivales de St del grupo mutans y lactobacillus. R.O.E. añol n $7,1996$.

18. Banting D, Bosma $\mathrm{M}$ y Bollmer B. Clinical effectiveness of a $0,12 \%$ chlorhexidine mouthrines over two years. J Dent Res 1989; 68 (Spec. Issue):1716-8.

19. Barnett P, Burgon-Lyon K, Smith J. Use of polyvinilpyrolidone to prevent clorhexidine stain formation in vitro. J Dent Res 1994; 73 (spec. Issue): 261 (Abstract).

20. Barkvoll P. Interaction between clorhexidine igluconate and sodium lauryl sulfate in vivo. J Clin Periodontol 1989, 16:593-95.

21. Bascones A, Manso F. Clorhexidina en odontoestomatología: conceptos actuales y revisión de la literatura. Avances en Odontoestomatología 1991;10:685-708.

22. Bascones A. Periodoncia Clínica e Implantología Oral. Madrid: Ediciones; Avances Médico-Dentales 2001, pp 455-71.

23. Bascones A, Morante S, Mateos L, Mata M, Poblet J. Influence of additional active ingredients on the effectiveness of non-alcoholic chlorhexidine mouthwashes: a ramdomized controlled trial. J Periodontol 2005 Sept; 76(9):1469-75.

24. Bay LM. Effect of toothbrushing with different concentrations of chlorhexidine on the development of dental plague and gingivitis. J Dent Res 1978; 57:181-5.

25. Bay LM y Russell BG. Effect of chlorhexidine on dental plague and gingivitis in mentally retarded children. Community Dent Oral Epidemiol 1975; 3: 267-70.

26. Bay LM y Langeback J. Effect of chlorhexidine-coated dressings of plague formation after gingivectomy. Scand J Dent Res 1978; 86: 303-4.

27. Beazley VC, Thranse P y Rólla G. Effect of mouthrinses with $\mathrm{NaF}$ of chlorhexidine on the amount of lipoteichoic acid formed in plaque. Scand J Dent Res 1980; 88:193200.

28. Ben Yaakow D y cols. Fluoride enhancement of chlorhexidine uptake by hydroxyapatite. Caries Res 1978; 12: 290-8.

29. Bergenholtz A y Hanstróm L. The plaque-inhibiting effect of hexeditine (Oraldene ${ }^{\circledR}$ ) -mouthwash compared to taht of chlorexidine. Community Dent Oral Epidemiol 1974; 2 : 70-4.

30. Berwick JE y Lessin ME. Effect of a clorhexidine gluconate oral rinse on the incidence of alveolar osteitis in mandibular third molar surgery. J Oral \& Maxillofac Surg 1990;48: 444-8.

31. Bokor M. The effect of hexetidine spray on dental plaque following periodontal surgery. J Clin Periodontol 1996 ; 23:1080-3.

32. Borrajo JL, Varela L, Castro G, Rodriguez-Nuñez I, Figueroa M, Torreira M. Efficacy of clorhexidine mouthrinses with and without alcohol: a clinical study. J Periodontol 2002; 73: 317-21.

33. Bosman CW y Powell RN.The reversal of locatized experimental gingivitis. J Clin Periodontol 1977;4:161-72.

34. Briner WW, Grossman RY, Buckner G y cols. Effect of chlorhexidine gluconate mouthrinse on plague bacteria.' Periodont Res 1986; 21 (Suppl.): 44-52.

35. Briner WW, Grossman E, BucknerY y cols. Assessment of susceptibility of plague bacteria to chlorhexidine after six months oral use. J Periodont Res 1986 (Suppl. 1):53-9. 
36. Briner W, Buckner R, Rebitski G y cols. Effect of two years use of $0,12 \%$ chlorhexidine on plague bacteria J Dent Res 1989; 68 (Spec. Issue):1719-21.

37. Brownstein CN, Briggs SD, Schweitzer KL y cols. Irrigation with chlorhexidine to resolve naturally occurring gingivitis. A methodologic study. J Clin Periodontol 1990; 17: 588-93.

38. Budtz-Jorgensen E. Hibitane in the treatment of oral candidiasis. J Clin Periodontol 1997; 4:117-25.

39. Carvalho MD, Tabchoury CM, Cury JA, Toledo S, Nogueira-Filho GR: Impact of mouthrinses on morning bad breath in healthy subjets. J Clin Periodontol 2004;31: 85-90.

40. Case DE. Safety of Hibitane (I). Laboratory experiments. J Clin Periodontol 1977;4:66-72.

41. Charles CH, Pan PC, Sturdivant L, Vincent JW. In vivo antimicrobial activity of an essencial oil-containning mouthrinse on interproximal plaque bacteria. J Clin Dent. 2000; 11(4): 94-7.

42. Charles C, Nresh C, Sharma B, Galustians J, Qaqish J, Macguire A, Vincent J. Comparative efficacy of an antiseptic mouthrinse and antiplaqe / antigingivitis dentifrice. A six month clinical trial. JADA, vol 132 May 2001.

43. Charles CH, Mostler KM, Bartels LL, Mankodi SM. Comparative antiplaque and antigingivitis effectiveness of a chlorhexidine and an essential oil mouthrinse: 6month clinical trial. J Clin Periodontol. 2004 Oct;31 (10):878-84.

44. Ciancio SG y Nisengard RJ. Control and prevention of Periodontal Disease. En: Nisengard RJ and Newman MG (Eds) Oral Microbiology and Inmunology. Philadelphia; WB Saunders Company, 1994: 385-90.

45. Claydon N, Manning CM, Darby, Dowman A, Ridge D, Smith S, Addy M. The effect of polivinylpyrrolidone on the clinical activity of $0,09 \%$ and $0,2 \%$ chlorhexidine mouthrinses. J Clin Periodontol 2001;28:1037-44.

46. Clark CD, Morgan J, MacEntee MI. Effects of a $1 \%$ chlorhexidine gel on the cariogenic bacteria in high-risk elders: a pilot study. Spec Care Dent 1991;11:101-3.

47. Collaert B, Edwardsson S, Attstróm R y cols. Rinsing with delmopinol 0,2\% and chlorhexidine 0,2\%: Short-term effect on salivary microbiology, plague and gingivitis. J Periodontol 1992;63:618-25.

48. Coventry J, Newman HN. Experimental use of a show release device employing chlorhexidine gluconate in areas of acute periodontal inflammation. J Clin Periodontol 1982 Mar;9(2):129-33.

49. Cosyn J, Wyn I, De Rouck T, Collys K, Bottenberg P, Matthijs S, Sabzevar MM. Short- term anti-plaque effect of two chlorhexidine varnishes. J Clin Periodontol 2005. Aug ;32(8):899-904.

50. Cumming BR y Lóe H. Optimal dosage and method of delivering chlorhexidine solutions for the inhibition of dental plaque. J Periodont Res 1973; 8: 57-62.

51. Davies R, Jensen S, Schiott $C$ y cols. The effect of topical application of chlorhexidine on the bacterial colonization of the teeth and gingiva.J Periodontol Res 1970; 5:96-101.

52. Delanghe G, Ghyselen J, Bollen C, van Steenberghe D, vandekerckhove BN, Feenstra L. An inventory of patients'response to treatment at a multidisciplinary breath odor clinic. Quintessence Int 1999;30:307-10.

53. Donazzan M y Trogon B. L'hexetidine en stomatologie. Rev Stomatol- Odontol Nord Fr 1963; 70:127-35.

54. Eley B. Antibacterial agents in the control of supragingival plaque- a review. British Dental Journal 1999; 186:286-9.

55. Ellingsen JE, Rölla G y Eriksen HM. Extrinsic dental stain caused by chlorhexidine and other desnaturing agents. J Clin Periodontol 1982;9:317-21.

56. Emilson CG. Susceptibility of various microorganisms to chlorhexidine. Scand J Dent Res 1977; 85: 255-65.

57. Emilson CG. Effect of clorhexidine gel treatment of Streptococcus mutans population in human saliva and dental plaque. Scand J Dent Res 1981; 89: 239-46.

58. Evans RT y cols. Comparison of antiplaque agents using an in vitro assay reflecting oral conditions. J Dent Res 1977 ; 56: 559-67.

59. Ferretti G, Largent B, Brown A y cols. The effect of chlorhexidine mouthrinse on mucositis, plaque, gingivitis and stain in bone marrow transplant patients. 
IADR Abstr. $n^{\circ} 546.63$ vd General Session, Las Vegas. J Dent Res 1985; 64 (Spec. Issue): 235.

60. Field EA, Nind D, Varga E, Martin MV. The effect of chlorhexidine irrigation on the incidence of dry socket: a pilot study. Br J Oral Maxillofac Surg. 1988. Octb;26 (5):395-401.

61. Flemming TF, Newman MG, Doherty FM y cols. Supragingival irrigation with $0,06 \%$ chlorhexidine in naturally occuring gingivitis. I. 6-Month clinical observations. J Periodontol 1990; 61:112-7.

62. Flemming TF. Irrigación supragingival como tratamiento complementario de la gingivitis y de la periodontitis. Periodoncia 1994; 4: 109-21.

63. Flötra L. Different modes of chlorhexidine application and related local side effects. J Periodont Res 1973;8: 41-4.

64. Flótra L, Gjermo P, Rólla G y Waerhaug J. A 4 mounth study on the effect of chlorhexidine mouth washes on 50 soldiers. Scand J Dent Res 1972;80:10-7.

65. Flötra L, Gjermo P, Röla G y Waerhaug J. Side effects of chlorhexidine mouthwashes. Scand J Dent Res 1971; 79:119-25.

66. Fordal O y Turnbull R. A review of the literature on use of chlorhexidine in dentistry. JADA 1986; 112: 863-69.

67. Francetti L, Fabro Del M, Basso M, Testori T, Taschieri S, Weinstein R: Chlorhexidine spray versus mouthwash in the control of dental plaque after implant surgery. J Clin Periodontol 2004;31: 857-62.

68. Giuliana G, Pizzo G, Milici M, Musobho G, Giangreco R. In vitro antifungicol properlis or mouthrinses contairniry antimicrobial agents.J Periodontal Res 1997; 68:729-33.

69. Gjermo P, Baastad KL y Rölla G. The plaque inhibiting capacity of 11 antibacterial compounds. J Periodontal Res 1970;5:102-9.

70. Gjermo P. Chlorhexidine in dental practice. J Clin Periodontol 1974;143-52.

71. Gjermo P, Bonesvoll P, Rolla G. Relationship between plaque inhibiting effect and retention of clorhexidine in the human oral cavity. Arch Oral Biol 1974;19:1031-4.
72. Gjermo P, Bonsvall P, Hjeljord L y Rólla G. Influence of variation of $\mathrm{pH}$ of chlorhexidine mouthrinses on oral retention and plaque inhibiting effect. Caries Res 1975; 9:74-82.

73. González Iglesias J. Historia de la Odontoestomatología Española. Madrid: Ediciones Avances Médico-Dentales, S.L; 1994.

74. Greenstain G, Berman C, Joffin R. Chlorhexidine- an adjunct to periodontal therapy. J Periodontol 1986;57: 370-7.

75. Grisi DC, Salvador SL, Figueiredo LC, Souza SL, Novaes AB, Grisi MF. Effect of a controlled-release chlorhexidine chip on clinical and microbiological parameters of periodontal síndrome. J Clin Periodontol. 2002 Octb;29(10):875-81.

76. Grossman E, Reiter G, Styrzenberg OP y cols. Six month study of effects of a chlorhexidine mouthrinse on gingivitis in adults. J Periodontal Res 1986; (Suppl.): 33-43.

77. Grossman E, Meckel AM, Isaacs RL y cols. A clinical comparison of antibacterial mouthrinses: Effects of chlorhexidine, phenolics and sanguinarine on dental plaque and gingivitis. J Periodontal 1989; 435-40.

78. Harper P, Milson S, Addy M, Morm J, Newcombe RG. An aproach to efficacy screeming of mouthrinses: Studies on a group of French products (II) inhibition of salivary bacteria and plaque in vivo. J Clin Periodontol 1995;22: 723-7.

79. Harper P, Milson S, Addy M, Morm J, Newcombe RG. An aproach to efficacy screeming of mouthrinses: Studies on a group of French products (I) stainning and antimicrobial properties in vitro. J Clin Periodontol 1995; 22:718-22.

80. Heyden G, Widmalm SE, Arwill T y Hedegaard B. The effects of chlorhexidine on the oral mucosa in patients with partial or complete dentures. Twelve case reports. Svenska Tanlkar Tidskrift 1971; 64: 239-46.

81. Hennesey Td. Some bacterial properties of chlorhexidine. J Periodont Res 1973;8(Suppl 12): 61-7.

82. Herrera D, Roldan S, Santacruz I, O'connor A, Sanz M. Actividad antimicrobiana en saliva de cuatro colutorios con clorhexidina. Periodoncia 2001;11(3):193-202.

83. Hunter L y Addy M. Chlorhexidine gluconate mouthwash in the management of minor aphthous ulceration. 
A double blind, placebo-controlled cross-over trial. $\mathrm{Br}$ Dent J 1987; 162: 106-9.

84. Jeffcoat MK, Palcanis KG, Weatherford TW, Reese M, Geurs NC, Flashner M. Use of a biodegradable chlorhexidine chip in the treatment of adult periodontitis: climicla and radiographics findings. J Periodontol 2000 Feb; $71(2)$ : 256-62.

85. Jeffcoat MK, Bray KS, Ciancio SG, Dentino AR, Fine DH, Gordon JM, Gunsolley JC, Killoy WJ, Loewnguth RA, Magnusson NI, Offenbacher S, Palcanis KG, Proskin HM, Finkelman RD, Flashner M. Adjunctive use of a subgingival controlled -release chlorhexidine chip reduces probing depth and improves attachment level compared with scaling and root planning alone. J Periodontol 1998. Sept; 69 (9) 989-97.

86. Jenkins S, Addy M, y Newcombe RG. Comparison of two commercially available chlorhexidine mouthrinses:II Effects on plaque reformation, gingivitis, and tooth staining. Clin Prev Dent. 1989 Nov-Dec;11(6):12-6.

87. Jenkins S, Addy M, y Newcombe RG. Dose responsse of chlorhexidine against plaque and comparison with triclosan. J Clin Periodontol 1994; 21:250-5.

88. Jenkins S, Yates M. A six months home usage trial of a $1 \%$ chlorhexidine toothpaste. J Clin Period 1993; 20:130-8.

89. Johansen JR, Gjermo P, Eriksen HM. Effect of two years use of chlorhexidine-containing dentifrices on plaque, gingivitis and caries. Scand J Periodont Res 1975;83: 288-92.

90. Jokinen MA. Prevention of postextraction bacteremia by local prophylaxis. Int J Oral Surg 1978; 7: 450-2.

91. Kenney EB, Saxe SR, Bowles RD. Effects of chlorhexidine on human polymorphonuclear leucocytes. Arch oral Biol. 1972 Nov;17 (11):1633-6.

92. Kornman KS. Topical Antimicrobial Agents: Individual Drugs. En: Newman MG and Kornman RS (Eds.) Antibiotic/Antimicrobial Use in Dental practice. Chicago: Quintessence Publishing Co. Ubc. 1990;98-109.

93. Kristoffersen T y Lie Tryggve. Necrotizing Gingivitis. En: Textbook of Clinical Periodontology. Lindhe J. (Ed.). Copenhague: Munsksgaard, 1984; 202-18.

94. Lang NP y Briner WN. Chemical control of gingivitis in man. JADA 1984;109: 223.
95. Lang N y Brecx M. Chlorhexidine digluconate, an agent for chemical plague control and prevention of gingival inflammation. J Periodont Res 1986; 21 (Suppl.): 7489.

96. Lang NP y Raber K. The use of oral irrigations as vehicles for the application of antimicrobial agents in chemical plague control. J Clin Periodontol 1981; 8: 177-88.

97. Lang NP, Hoz P, Graf $\mathrm{H}$ y cols. Effects of supervised chlorhexidine mouthrinses in children. A longitudinal clinical trial. J Periodontal Res 1982;17: 101-11.

98. Leydiger j. Apropos de l'utilisation de l'hexétidine comme antiseptique et cicatrisant en odontostomatologie. Inf Dent 1961;5:158-9.

99. Liljemark WF, Schaver SV y Bloomquist CC. Compounds which affect the adherence of Streptococcus sanguis and Streptococcus mutans to hydroxyapatite. J Dent Res 1978;57:373-9.

100. Lindhe J, Karring T, Lang N. Periodontología clínica e implantología odontológica. Capítulo 16:465-88.

101. Lindhe J y Slots J. Juvenile periodontitis. En: Textbook of Clinical Periodontology. Copenhague: Munskgaard, 1984:188-201.

102. Lindhe J, Hamp SE, Loe H. Plaque induced periodontal disease in beagle dogs. A 4-year clinical, roentgenographical and histometrical study. J Periodontal Res 1975 Nov;10(5):243-55.

103. Lindhe J, Heijl L, Goodson JM, Socransky SS. Local tetracycline using hollow fiber devices in periodontal therapy. J Clin Periodontol 1979 Jun;6(3):141-9.

104. Löe H y Schiott CR. The effect of moutrinses and topical application of chlorhexidine on development of dental plaque and gingivitis in man. J Periodont Res 1970;5: 79-83.

105. Löe H., Theilade E., \& Jensen S.B. (1965) Experimental gingivitis in man. Journal of Periodontology 1965;36: 177-87.

106. Löe H, Schiott CR, Glavind L y Karring Y. Two years oral use of chlorhexidine in man. I. General design and clinical effects. J Periodont Res 1976;11:135-44.

107. Loesche W. Chemoterapy of dental plaque infections. Oral Sci Rev 1976;9:65-107. 
108. Loe H, Frithjof R, Von der Feh y Schiótt R. Inhibition of experimental caries by plague prevention. The effect of chlorhexidine mouthrinses. Scand J Dent Res 1972; 80:1-9.

109. López y cols. Estudio clínico abierto de un gel de clorhexidina en el control de la inflamación gingival (ensayo entre gel vs colutorio). Avances en Periodoncia, 1997; 9:49-61.

110. Luoma J. Chlorhexidine solutions, gels and varnishes in caries prevention. Proc Finn Dent Soc, 1992;88:14753.

111. Mackenzie IC, Nuki K, Löe H, Schiött CR.Two years'oral use of chlorhexidine in manV. Effects on stratum corneum of oral mucosa. J Periodont Res 1976;11:16571.

112. Manau C, Martínez Lizan I, Ramon Torrel JM y cols. Efectividad comparativa de un colutorio de fluoruro estañoso y fluoruro de aminas (Lemirol ${ }^{\circledR}$ ) en el control de placa, gingivitis y E. mutans salivaris: Resultados a los tres meses. Actualidad Odontoestomatológica Española 1993;422:47-53.

113. Marsh PD. Inhibition by the antimicrobial agent of acid production and sugar transport in oral streptococcal bacteria. Arch Oral Biol 1983;28:233-40.

114. Martindale. The Extra pharmacopoeia. 30 Ed. London: The Pharmaceutical Press 1993:781-805.

115. Maruniak J, Clark WB, Walker CB, Magnusson I, Marks RG, Taylor M and Clouser B. The effect of 3 mouthrinses on plaque and gingivitis development. Clin Periodontol 1992;19:19-23.

116. Mendieta C, Vallcorba N, Binney A y Addy M. Comparison of 2 chlorhexidine mouthwashes on plaque regrowth in vivo and dietary staining in vitro. J Clin Periodontol 1994;21:296-300.

117. Moghadam BK, Drisko CL, Gier RE. Chlorhexidine mouthwash-induced fixed drug eruption. Case report and review of the literature. Oral Surg Oral Med Oral Pathol7 1:431-4, 1991.

118. Moran J, Addy M y Newcombe R. A clinical trial to assess the efficacy of sanguinarine - Zinc mouthrinse $\left(\right.$ Veadent ${ }^{\circledR}$ ) compared with chlorhexidine mouthrinse $\left(\right.$ Corsodyl $^{\circledR}$ ). J Clin Periodontol 1988;15:612-6.
119. Moran J, Newcombe R y Addy M. Comparison of a phenolic and a 0,2\% chlorhexidine mouthwash on the development of plaque and gingivitis. Clin Prevent Dent 1991;13:31-5.

120. Newman MG, Sanz M, Nachnani S y cols. Effect of 0,12\% chlorhexidine on bacterial recolonization following periodontal surgery. J Periodontol 1989;60: 577-81.

121. Nordbo H, Sorensen R y Sonju T. Furfurals in chlorhexidine discoloured pellicles. Scand J Dent Res 1977;85: 606-9.

122. Novikov LL y cols. Effects of inorganic and organic fluorides combined with molybdenum and chlorhexidine upon processes of metabolism, fluoride content and cariosity of the teeth of wistar rats. Zahn Mund Kieferheilkd 1980;68:3-8.

123. Okano M, Nomura M, Hata S, Okada N, Sato K, Kitano Y. Anaphylactic symtoms due to chlorhexidine gluconato. Arch Dermatol 1989;125: 50-2.

124. Olsen I. Denture stomatitis. Relapse tendency and removal of acquired discolorations in long-term denture disinfection with chlorhexidine. Acta Odontol Scand 1975;33:111-4.

125. Olsen I. Denture stomatitis. The clinical effects of chlorhexidine and amphotericin B. Acta Odont Scand 1975; 33:47-52.

126. O'Neil TC. The use of chlorhexidine mouthwash in the control of gingival inflammation. Br Dent J 1976; 141 :27680.

127. Pai MR, Acharya LD, Udupa N. The effect of two different dental gels and a mouthwash on plaque and gingival scores: a six-week clinical study. Int Dent J. 2004 Aug; 54(4):219-23.

128. Paunio KV, Knvuttila M y Mielitynen $\mathrm{H}$. The effect of chlorhexidine gluconate on the formation of experimental granulation tissue. J Periodontol 1978;49:92-5.

129. Piccione N. Use of chlorhexidine in the therapy of some stomatological diseases. Minerva Stomat 1979; 28:20914.

130. Pienihükkinen y cols. Comparison of the efficacy of $40 \%$ chlorhexidine varnish and $1 \%$ chlorhexidine fluoride gel in decreasing the level of salivary mutans St. Carier Res 1997;29:62-7. 
131. Pluss EM, Egelberger PR y Rateitschak KH. Effects of clorhexidine on dental plaque formation under periodontal pack. J Clin Periodontol 1975; 2:136-42.

132. Pontefract H, Hughis J, Kemp K, Yates R, Newconbe R, Addy M. Therosive effects of same mouthrinses on enamel. A study in situ. J Clin Periodontol 2001; 28:319-24.

133. Quirynen M, Auontroodt P, Peeters W, Pauwels M, Couche W, Van Steenberghe. Effect of different clorhexidine formulations in mouthrinses on de novo plaque formation. J Clin Periodontol 2001; 1127-36.

134. Quirynen M, Soers C, Desnyder M, Dekeyser C, Pauwels M, van Steenberghe D A 0,05\% cetyl pyridinium chloride/0,05\% chlorhexidine mouth rinse during maintenance phase after initial periodontal therapy. J Clin Periodontol 2005;32:390-400 doi: 10,1111/j.160005lx.2005.00685.x.

135. Quirynen M, Zhao H, Soers C, Dekeyser C, Pauwels M, Coucke W, van Steenberghe D. The impact of periodontal therapy and the adjunctive effect of antiseptics on breath odor-related outcome variables: a double-blind randomized study. J Periodontal 2005;76:705-12.

136. Ragno JR y Szkntwik AJ. Evaluation of 0,12\% chlorhexidine rinse on the prevention of alveolar osteitis. Oral Surg Oral Med Oral Pathol 1991;72: 524-6.

137. Rebstein F y cols. Plak-out and Broxojet 3007. Clinical study. SSO 1978;88:1155-65.

138. Reich E, Arweiler N, Neuschul L. Alcohol free mouthrinse solutions to reduce supragingival plaque regrowth and vitality. A controlled clinical study. J Clin Periodontol $2001 ; 28: 168-74$.

139. Ribeiro DA, Bazo AP, da Silva Franchi CA, Marques MEA, Salvadori DMF, Chlorhexidine induces DNA damage in rat peripheral leukocytes and oral mucosal cells. J Periodont Res 2004; 39; 358-361.

140. Roldán S, Herrera D, Santa-Cruz I, O'Connor A, González I, Sanz M. Comparative effects of diferent chlorhexidine Ruth-rinse formulations on volatile sulphur compounds and salivary bacterial counts. J Clin Periodontol 2004;31:1128-34.

141. Roldan S, Herrera D, O'connor A, González I, Sanz M. A combined therapeutic approach to manage oral halitosis: a 3 month prospective case series. J Periodontol 2005;76:1025-33.
142. Rölla G y Melsen B. On the mechanism of the plaque inhibition by chñprjexodome. J Dent Res 1975; (Spec. Issue B):57-62.

143. Ross N, ManKodi S, Mostler K, Charles C, Bortels L. J Clin Periodontol 1993; 20:279-81.

144. Rusell BG y Bay LM. Oral use of chlorhexidine gluconate toothpaste in epileptic children. Scand J Dent Res 1978; 86: 52-7.

145. Rushton A. Safety of hibitane. II. Human experience. J Clin Periodont 1977;5:73-9.

146. Santos S, Herrera D, Lopez E, O'Connor A, Gonzalez I, Sanz M. A randomized clinical trial on the short-term clinical and microbiological effects of the adjunctive use of a $0,05 \%$ chlorhexidine mouth rinse for patients in supportive periodontal care. J Clin Periodontol. 2004 Jan;31(1):45-51.

147. Sanz M, Newman MG. Clinical enhancement of postperiodontal surgical therapy by a $0,12 \%$ clorhexidine gluconate mouthrinse. J Periodontol 1989;60: 570-6.

148. Sanz M y cols. The effect of a dentifrice containnin chlorhexidine and $\mathrm{Zn}$ on plaque, gingivitis, calculus and tooth stainning. J Clin Periodontol 1994;21:431-43.

149. Schiött CR. The effect of chlorhexidine mouthrinse on human oral flora. J Periodont Res 1970;5:84-9.

150. Schiött CR, Löe H y Brinner WW. Two years oral use of clorhexidine in man IV. Effect on various medical parameters. J Periodontal Res 1976;11:158-64.

151. Schiott CR. Effect of chlorhexidine on the microflora of the oral cavity. J Periodont Res 1973;8(Suppl. 12):710.

152. Segreto VA, Collins EM, Beiswanger BB y cols. A comparison of mouthrinses containning two concentrations of clorhexidine. J Periodontal Res 1986;21 (suppl)23-32.

153. Sekino S, Ramberg P, Guzin Uzel N, Socransky S, Lindhe J: The effect of a chlorhexidine regimen on the novo plaque formation. J Clin Periodontol 2004;31: 609-14.

154. Siegrist BE, Gusberti FA, Brecx MC y cols. Efficacy of supervised rinsing with chlorhexidine digluconate in comparison to phenolic and plant alkaloid compounds. J Periodont Res 1986;21(Suppl.):60-73. 
155. Slots J. Subgingival microflora and periodontal disease. J Clin Periodontol 1979;6:351-82.

156. Simring M, Golberg M, Carron R y cols. Deodorization ans healing: hexetidine in periodontal surgery. Oral Surg Oral Med Oral Pathol 1963;16:1432-42.

157. Socransky SS. Microbiology of periodontal disease. Present statuts and future considerations. J Periodont 1977;48:497-504.

158. Soskolne WA, Heasman PA, Stabholz A, Smart GJ, Palmer M, Flashner M, Newmann HN. Sustained local delivery of chlorhexidine in the treatment of periodontitis: a multicenter study. J Periodontol 1997 Jan; 68 (1): 32-8.

159. Southard S, Drisko C, Killoy W y cols. The effect of $2 \%$ chlorhexidine digluconate irrigation on clinical parameters and the level of Bacteroides gingivalis in periodontal pockets. J Periodont 1989; 60: 302-9.

160. Spiers ASD, Diaz SF y López JA. Infection prevention in patients with cancer: microbiological evaluation of portable laminar air flow isolation, topical chlorhexidine and oral non-absorbable anfibio-tics. J Hyg 1980;84: 457-65.

161. Steenberghe V, Quiryne M, Avontroodt P, Peeters W, Pauwels M, Rouche W. Effect of different clorhexidine formulations in mouthrinses on de novo plaque formation. J Clin Periodontol 2001;1127-36.

162. Straub B, Chaumaz D, Robin O. Influence de la présence d'alcool sur les modifications du goût induites par deix bains de bouche á base de chlorhexidine á 0,12\%. J Párodontol 2001;23:343-8.

163. Tanner ACR, Dtink JL, Ebersole JL y Socransky SS. Wollinella recta, Campylobacter concisus, Bacteroides gracilis and Eikenella corrodens from periodontal lesions. J Periodont Res 1987; 22: 327-30.

164. Tjernberg A. Influence of oral hygiene measures on the development of alveolitis sicca dolorssa after surgical removal of mandibular third molars. Int J Oral Surg 1979; 8:430-4.

165. Usher PJ. Oral hygiene in mentally handicapped children. A pilot study of the use of chlorhexidine gel. Br Dent J 1975;138: 217-21.

166. Van Strydonck, Timmerman MF, Van der Velden U, Van der Weijden, GA: The anti-plaque efficacy of a chlorhexidine mouthrinse used in combination with toothbrushing with dentifrice. J Clin Periodontol 2004; 31:691-5.

167. Veksler. AE, Kayouz GS y Newman MG. Reduction of salivary bacteria by pre-procedural rinses with chlorhexidine 0,12\%. J Periodontol 1991;62:649-51.

168. Westfelt E, Nyman S, Lindhe J y Socransky SS. Use of clorhexidine as a plaque control measure following surgical treatment of periodontal disease. J Clin Periodontol 1983;10: 22-36.

169. Yaegaki K, Coil JM. Examination, classification and treatment halitosis; clinical perspectives. J Can Dent Assoc 2000; 66 : 257-261.

170. Yankell S, Moreno O, Soffin A, Lowary R y Gold W. Effects of chlorhexidine and four antimicrobial compounds on plaque, gingivitis and staining in beagle dogs. J Dent Res 1982; 61:1089-93.

171. Yévenes I, Reyes J, Campos N, Saragoni V. Efecto inhibitorio en placa microbiana y propiedades antibacterianas de enjuagatorios de clorhexidina. 2002. Facultad de Odontología, Universidad de Chile. (Avances en Periodoncia e Implantología Oral) (en prensa).

172. Yiu y cols. Clinical efficacy of dentifrice in the control of calculus, plaque and gingivitis. Quintessence Int 1993; 24:181-8.

173. Zickert I Emilson CG y Krasse B. Effect of caries preventive measures in children highly infected with Streptococcus mutans. Arch oral Biol 1982 b;27:861-8. 